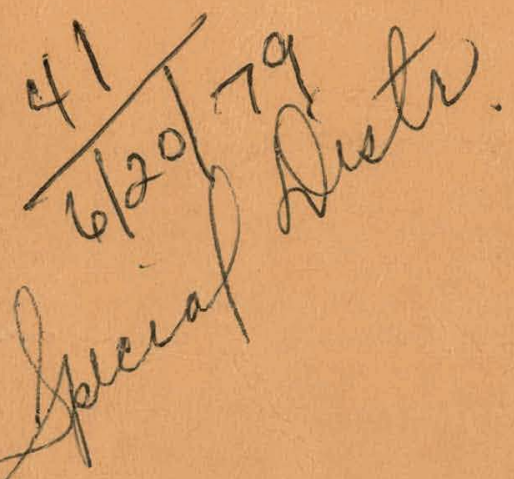

WAPD-TM-1285 DOE RESEARCH AND DEVELOPMENT REPORT

RADIOLOGICAL CONTROL ASPECTS OF THE FABRICATION OF THE LIGHT WATER BREEDER REACTOR CORE

(LWBR Development Program)

MAY 1979

CONTRACT EY-76-C-11-0014

BETTIS ATOMIC POWER LABORATORY WEST MIFFLIN. PENNSYLVANIA

Operated for the U. S. Department of Energy by WESTINGHOUSE ELECTRIC CORPORATION 


\section{DISCLAIMER}

This report was prepared as an account of work sponsored by an agency of the United States Government. Neither the United States Government nor any agency Thereof, nor any of their employees, makes any warranty, express or implied, or assumes any legal liability or responsibility for the accuracy, completeness, or usefulness of any information, apparatus, product, or process disclosed, or represents that its use would not infringe privately owned rights. Reference herein to any specific commercial product, process, or service by trade name, trademark, manufacturer, or otherwise does not necessarily constitute or imply its endorsement, recommendation, or favoring by the United States Government or any agency thereof. The views and opinions of authors expressed herein do not necessarily state or reflect those of the United States Government or any agency thereof. 


\section{DISCLAIMER}

Portions of this document may be illegible in electronic image products. Images are produced from the best available original document. 
WAPD-TM-1285

Special External Distribution

\section{RADIOLOGICAL CONTROL ASPECTS OF THE FABRICATION OF THE LIGHT WATER BREEDER REACTOR CORE \\ (LWBR Development Program)}

Edited by B. G. Schultz

May 1979

Contract EY-76-C-11-0014

Printed in the United States of America

Available from the

National Technical Information Service

U: S. Department of Commerce 5285 Port Royal Road

Springfield, Virginia 22151

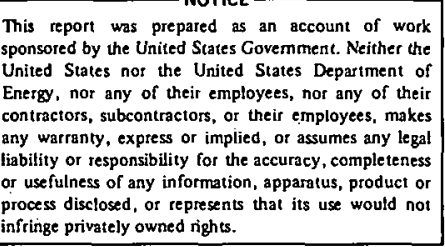

infringe privately owned rights.

NOTE

This document is an interim memorandum prepared primarily for internal reference and does not represent a final expression of the opinion of Westinghouse. When this memorandum is distributed externally, it is with the express understanding that Westinghouse makes no representation as to completeness, accuracy, or usability of information contained therein.

\section{BETTIS ATOMIC POWER LABORATORY WEST MIFFLIN, PENNSYLVANIA} WESTINGHOUSE ELECTRIC CORPORATION 


\section{NOTICE}

This report was prepared as an account of work sponsored by the United States Government. Neither the United States, nor the United States Department of Energy, nor any of their employees, nor any of their contractors, subcontractors, or their employees, makes any warranty, express or implied, or assumes any legal liability or responsibility for the accuracy, completeness or usefulness of any information, apparatus, product or process disclosed, or represents that its use would not infringe privately owned rights. 


\section{FOREWORD}

The Shippingport Atomic Power Station located in Shippingport, Pennsylvania was the first large-scale, central-station nuclear power plant in the United States and the first plant of such size in the world operated solely to produce electric power. This program was started in 1953 to confirm the practical application of nuclear power for large-scale electric power generation. It has provided much of the technology being used for design and operation of the commercial, central-station nuclear power plants now in use.

Subsequent to development and successful operation of the Pressurized Water Reactor in the DOE-owned reactor plant at the Shippingport Atomic Power Station, the Atomic Energy Commission in 1965 undertook a research and development program to design and build a Light Water Breeder Reactor core for operation in the Shippingport Station.

The objective of the Light Water Breeder Reactor (LWBR) program has been to develop a technology that would significantly improve the utilization of the nation's nuclear fuel resources employing the well-established water reactor technology. To achieve this objective, work has been directed toward analysis, design, component tests, and fabrication of a water-cooled, thorium oxide fuel cycle breeder reactor for installation and operation at the Shippingport Station. The LWBR core started operation in the Shippingport Station in the Fall of 1977 and is expected to be operated for about 3 to 4 years. At the end of this period, the core will be removed and the spent fuel shipped to the Naval Reactors Expended Core Facility for a detailed examination to verify core performance including an evaluation of breeding characteristics.

In 1976, with fabrication of the Shippingport LWBR core nearing completion, the Energy Research and Development Administration established the Advanced Water Breeder Applications (AWBA) program to develop and disseminate technical information which would assist U.S. industry in evaluating the LWBR concept for commercial-scale applications. The program will explore some of the problems that would be faced by industry in adapting technology confirmed in the LWBR program. Information to be developed includes concepts for commercial-scale prebreeder cores which would produce uranium-233 for light water breeder cores while producing electric power, improvements for breeder cores based on the lechnology developed to tabricate and operate the Shippingport LWBR core, and other information and technology to aid in evaluating commercial-scale application of the LWBR concept.

All three development programs (Pressurized Water Reactor, Light Water Breeder Reactor, and Advanced Water Breeder Applications) have been administered by the Division of Naval Reactors with the goal of developing practical improvements in the utilization of nuclear fuel resources for generation of electrical energy using water-cooled nuclear reactors.

Technical information developed under the Shippingport, LWBR, and AWBA programs has been and will continue to be published in technical memoranda, one of which is this present report. 
II. LWBR FUEL MATERIALS

A. General Description

B. Characteristic Radiation Levels

A. Introduction

B. External Radiation Exposure Limits

1. Whole Body and Critical Organs Exposure to Penetrating Radiation

2. Exposure to the Skin of the Whole Body

3. Exposure to the Extremities and Other Organs

4. On-site Uncontrolled Area Exposure Rates

C. Contamination Control Limits

1. Airborne Radioactivity Concentration Guides

2. Surface Contamination Limits

3. Radioactive Liquid Waste

4. Radioactive Solid Waste

D. Controlled Areas

1. Introduction

2. Restrictions on Controlled Ãreas

3. Controlled Area Limits

4. Radiological Work Permit

IV. PROGRAM OUTLINE

A. Introduction

B. General Criteria

1. External Exposure Control Criteria

2. Contamination Control Criteria

C. Radiological Control Procedures

D. Training

E. LWBR Core Radiological Surveillance Program

F. Radiation Exposure Control Program

1. Monitoring

2. Rem Reduction Program

3. Management Control

V. DFTAIIF.D DESCRIPTION AND OPERATIONAL. EXPERIENCF.

A. Introduction 10

B. Ceramic Processing Facility 10

1. Introduction 10

2. Manufacturing Operations 12

3. Maintenance and Repair Control 12

4. Ventilation System 12

5. Liquid and Gaseous Effluent Control $\quad 12$

6. Solid Waste Disposal 13

7. Area Monitoring and Surveillance

8. External and Internal Exposure Monitoring

C. Binary Development Area 13

1. Introduction 13

2. Contamination Control 13

3. External Exposure Control 23 
D. Fuel Rod Facility $\quad 24$

1. Introduction 24

2. BC Aisle 26

3. Core Module Assembly Area (CMAA) 27

VI. LWBR OPERATIONAL SUPPORT GROUP

A. Introduction $\quad 34$

B. Glovebox Gloves and Protective Gloves

C. Containment Development

1. Area Contamination Containment Devices $\quad 35$

2. Glovebox Bag-In/Bag-Out Sleeving $\quad 36$

D. Binary Development Area Protective Clothing Requirements 36

E. Rem Reduction Actions 36

$\begin{array}{ll}\text { F. Surveillance } & 39\end{array}$

VII. SUMMARY OF OVERALL RESULTS AND LESSONS LEARNED 39

A. Radioactive Material Containment 39

B. Radiation Exposure Control $\quad 42$

C. Lessons Learned $\quad \cdot \quad 42$

1. Contamination Containment Criteria

2. Radiation Exposure Reduction $\quad 43$

VIII. ACKNOWLEDGEMENTS 43

IX. REFERENCES

APPENDIX A-RADIOLOGICAL SURVEILLANCE PLAN-LWBR CORE MANUFACTURING PROGRAM

1. INIRONUCIION A-1

II. MONITORING FOR AIRBORNE RADIOACTIVITY A-1

A. Ceneral Air Sampling A-l

B. Continuous Air Moniturs A-1

C. Giaseous Éttluent (E'xhaust) Monitoring A-1

III. AREA RADIATION MONITORING A-1

A. Continuous Area Gamma Monitors A-1

B. Startup Surveys

C. Routine and Other Special Surveys

IV. CONTAMINATION MONITORING A-2

A. Personnel Frisking A-2

B. Laundry Monitoring $\quad \Lambda-3$

C. Area Monitoring A-2.

1. Ceramic Processing Facility A-2

2. Binary Development Area A-3

D. Material Surveys

V. LIQUID WASTE MONITORING A-3

VI. SOLID WASTE MONITORING A-3 
VII. PERSONNEL MONITORING

A. External Exposure Monitoring

B. Internal Exposure Monitoring

C. Extremity Monitoring

APPENDIX B-SHIELD DESIGN BASIS AND PERSONNEL EXPOSURE ESTIMATES

I. INTRODUCTION

II. POWDER AND PELLET PRODUCTION

III. FUEL ROD PROCESSING

IV. CORE ASSEMBLY OPERATIONS

APPENDIX C-TYPICAL AVERAGE MONTHLY PERSONNEL RADIATION EXPOSURES

\section{LIST OF ILLUSTRATIONS}

Figure

\section{Title}

Relative Gamma Emission versus Time Following Purification

LWBR Core Manufacturing Process Flow Chart

Typical Section of Glovebox Processing Line

Binary Development Area Layout

Binary Development Area Equipment Layout and Traffic Pattern

Binary Development Area $\mathrm{CO}_{2}$ Binder Removal Furnace

Binary Development Area Furnace Room

Binary Development Area Controlled Work Zone

Cross Section of a Shielded Glovebox

Radiation Intensity Buildup in Pellet Grinding Gloveboxes

Shielded Work Tables

Fuel Rod Storage Vault

Core Module Assembly Area

LWBR Blanket Module Storage Area

CMAA Binary Fuel Rod Handling/Pulling Operations

Top View of CMAA Binary Fuel Rod Handling Operations

Page 
This report presents a description of the radiological control aspects of the fabrication of the Light Water Breeder Reactor (LWBR) core. Included are the radiological control criteria applied for the design and use of fabrication facilities, the controls and limits imposed to minimize radiation exposure to personnel, and an evaluation of the applied radiological program in meeting the program objectives. The goal of the LWBR program is to develop the technology to breed in light water reactors so that nuclear fuel may be used significantly more efficiently in these reactors. This technology is being developed by designing and fabricating a breeder reactor core, utilizing thoria $\left(\mathrm{ThO}_{2}\right)$ and binary thoria-urania ( $\mathrm{ThO}_{2}{ }^{233} \mathrm{UO}_{2}$ ) fuel, to be operated in the existing pressurized water reactor plant owned by the Department of Energy at Shippingport. Pennsylvania.

\title{
RADIOLOGICAL CONTROL ASPECTS OF THE FABRICATION OF THE LIGHT WATER BREEDER REACTOR CORE (LWBR Development Program)
}

\author{
Edited by B. G. Schultz
}

\section{INTRODUCTION}

This report presents a description of the radiological control programs applied for the fabrication of the Light Water Breeder Reactor (LWBR) core at the Bettis Atomic Power Laboratory in West Mifflin, Pennsylvania. The report details the radiological control criteria applied for the design and use of fabrication facilities, the controls and limits imposed to minimize radiation exposure to personnel associated with core manufacture and assembly and an evaluation of the applied radiological program in meeting the program objectives.

The objective of the radiological controls established for the manufacture of LWBR fuel elements and assembly of the core modules was to ensure that all personnel on-site as well as all residents living in the plant vicinity would receive radiation exposures as low as is reasonably achievable and would in no case exceed the maximum permissible exposure limits for radiation workers or population groups specified in References 1 and 2 . The facilities, protective clothing and equipment, and procedures used were designed to maintain total containment of all radioactive materials. Shielding was utilized to keep personnel exposures at the lowest practicable levels.

\section{LWBR FUEL MATERIALS}

\section{A. General Description}

The LWBK core consists of 24 hexagonal modules arranged in a symmetric array and surrounded by a reflector region of 15 modules. The core is 8.7 feet high, 7.7 feet in diameter, and contains approximately 42 metric tons of $\mathrm{THO}_{2}$ powder and 0.5 metric tons of ${ }^{233} \mathrm{UO}_{2}$ powder.
The powder is formed into ceramic pellets and loaded into Zircaloy tubes, which are then sealed at both ends by welded end closures to form fuel rods. These fuel rods are arranged to form the hexagonal modules. There are 3048 rods containing only $\mathrm{ThO}_{2}$ pellets and 14,247 rods containing both $\mathrm{ThO}_{2}$ and $\mathrm{ThO}_{2}-{ }^{233} \mathrm{UO}_{2}$ pellets. The binary pellet uranium content ranges from 1.2 to 5.2 percent ${ }^{233} \mathrm{U}$.

\section{B. Characteristic Radiation Levels}

During the manufacture of the LWBR core fuel elements, a large quantity of $\mathrm{ThO}_{2}$ powder and ${ }^{23} \mathrm{UO}_{2}$ powder material had to be handled in both unclad and clad forms. The ${ }^{233} \mathrm{U}$ and ${ }^{232} \mathrm{U}$ and decay daughters present as impurities in the ${ }^{233} \mathrm{U}$ were high alpha specific activity radio-nuclides (specific activities: $9.48 \times 10^{-3} \mathrm{Ci} / \mathrm{g}$ for ${ }^{233} \mathrm{U}$ and $20.8 \mathrm{Ci} / \mathrm{g}$ for ${ }^{232} \mathrm{U}$ ) which presented a significant contamination potential during manufacturing operations with unclad fuel materials. Additronally, several of the ${ }^{232} U$ daughters are high energy, beta-gamma emitters (i.e., ${ }^{208} \mathrm{Tl}$ with gamma energies up to $2.6 \mathrm{l} \mathrm{Mev}$ ) which could result in high radiation fields during operations with both clad and unclad binary fuel material. For these reasons, prime consideration in designing the manufacturing facilities for binary fuel was given to providing total containment for contamination control and shielding for radiation exposure control.

The ${ }^{233} \mathrm{U}$ material used for LWBR core manufacture was produced by neutron irradiation of thoria. It was specified that the ${ }^{232} \mathrm{U}$ content of this ${ }^{233} \mathrm{U}$ material be limited to less than $10 \mathrm{ppm}$ to minimize core fabrication difficulties associated with high gamma radiation levels resulting from the 
buildup of the ${ }^{232} \mathrm{U}$ daughters. The material used for the LWBR core had an average of $7.5 \mathrm{ppm}^{232} \mathrm{U}$ which is much less than that expected in material recycled through power reactors. (According to current calculational analyses, the ${ }^{232} \mathrm{U}$ content will increase during successive irradiations to a typical equilibrium ${ }^{23} \mathrm{U}$ material containing about 2500 ppm ${ }^{232} \mathrm{U}$.)

The ${ }^{233} \mathrm{U}$ material was purified by chemical separation of the ${ }^{232} \mathrm{U}$ daughters from the ${ }^{233} \mathrm{U}$ just prior to its use. To minimize the buildup of gamma radiation following this purification step as shown in Figure 1, key time periods, i.e. calendar days, were established for completing certain processing steps. These key periods were used as the basis for equipment shielding designs and detailing certain of the processing operations to minimize personnel radiation exposures. These key periods are shown on Figure $l$ and are further discussed in Appendix B.

The decay daughters of ${ }^{232} \mathrm{Th}$ with its much lower specific activity of $1.09 \times 10^{-7} \mathrm{Ci} / \mathrm{g}$ were a minor contributor to the gamma radiation levels of the binary fuel, so that chemical purification of the ${ }^{232} \mathrm{Th}$ material to remove the decay daughters was not required just prior to fuel fabrication.

Typical gamma radiation levels which were measured during core manufacture were as follows:
1. ${ }^{233} \mathrm{UO}_{2}$ powder received from the vendor in 4-inch-diameter by 3-inch-high cans, each containing approximately 500 grams of ${ }^{233} \mathrm{UO}_{2}$, had a maximum gamma radiation level 21 days after purification from its ${ }^{232} \mathrm{U}$ daughters of $40 \mathrm{mrem} / \mathrm{hr}$ on contact and $5 \mathrm{mrem} / \mathrm{hr}$ at $\mathrm{l}$ foot.

2. A 4-inch by 9 -inch by 3/4-inch stainless steel tray containing about 840 seed pellets (4.2 kilograms of $\mathrm{ThO}_{2}{ }^{233} \mathrm{UO}_{2}$ pellets containing 5.2 weight percent ${ }^{233} \mathrm{U}$ ) had the following gamma readings 439 days after purification of the ${ }^{233} \mathrm{UO}_{2}$ :

Highest readings on

top of tray- $900 \mathrm{mrem} / \mathrm{hr}$ on contact and 45 $\mathrm{mrem} / \mathrm{hr}$ at $\mathrm{l}$ foot.

Highest readings on

side of tray $-350 \mathrm{mrem} / \mathrm{hr}$ on contact and 22 $\mathrm{mrem} / \mathrm{hr}$ at $\mathrm{l}$ foot.

3. $\bar{A}$ fuel rod box containing eight blanket fuel rods with an average fuel age of 184 days had a maximum gamma radiation level of $32 \mathrm{mrem} / \mathrm{hr}$ at $\mathrm{l}$ foot about the midpoint along the length of the box. Contact readings on the ends of the box were about $1 \mathrm{mrem} / \mathrm{hr}$.

4. A completed blanket module containing 443 rods had gamma radiation levels of $600 \mathrm{mrem} / \mathrm{hr}$ at $1 \mathrm{inch}$ and $240 \mathrm{mrem} / \mathrm{hr}$ at 1 foot as measured about the midpoint along

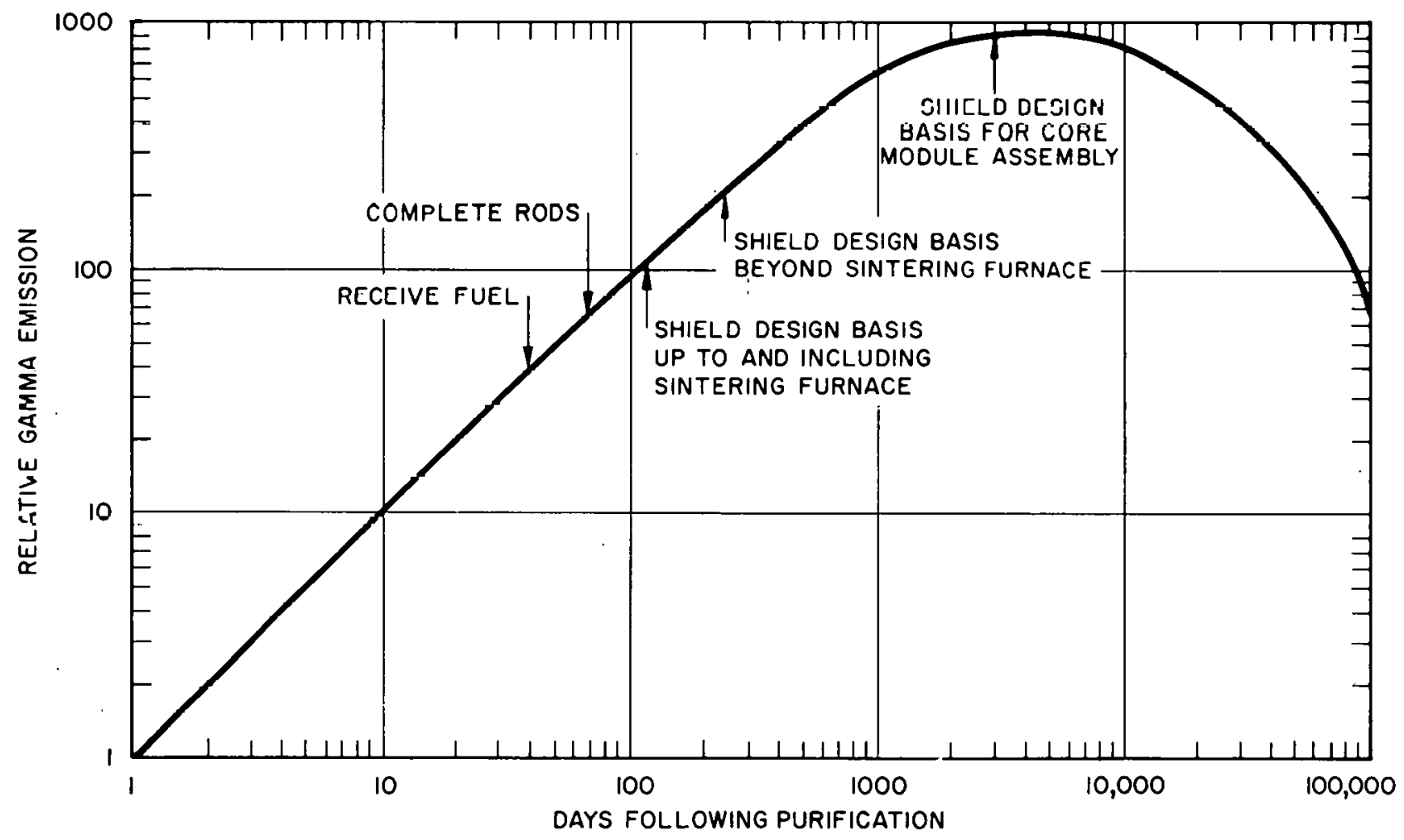

Figure 1. Relative Gamma Emission versus Time Following Purification 
the length of the module. These levels dropped off at the ends of the modules to about $12 \mathrm{mrem} / \mathrm{hr}$ at $1 \mathrm{inch}$ and $26 \mathrm{mrem} / \mathrm{hr}$ at 1 foot, where radiation was contributed by the center of the module.

\section{RADIOLOGICAL CONTROL OBJECTIVES AND ESTAB- LISHED LIMITS}

\section{A. Introduction}

The radiological control objectives for the LWBR fuel manufacturing program were to minimize personnel radiation exposures both on-site as well as off-site to the lowest practicable levels and to prevent deposition of radioactive materials on personnel, either externally or internally. To aid in accomplishing these objectives, the following limits and controls were applied for radiological control.

\section{B. External Radiation Exposure Limits}

The radiation exposure limits below were applied to all occupational radiation exposures from both external and internal sources of radiation. (Medical, dental, and natural background radiation exposures were excluded.) These limits were based on the requirements of References 1 and 2, which were derived so that no detectable biological effects would be anticipated even if an individual were exposed at the maximum limit for his entire working lifetime. Nevertheless, personnel were instructed and encouraged to maintain their own exposures as low as practicable below these limits.

\section{Whole Body and Critical Organs* Expo- sure to Penetrating Radiation}

The limits listed below for whole body exposure applied to general exposures of penetrating radiation to major portions of the body and also to exposures of certain critical organs*. If the radiological exposure from an internally deposited radioactive material were to exceed 10 percent of these limits, the external exposure limits would be reduced by the estimated internal radiological exposure in order to avoid exceeding the limits. Other limits which applicd to radiation of luw penetrating power, such as gamma radiation of less than $0.1 \mathrm{Mev}$ energy and heta radiation, are discussed in Item 3 below. a. Quarterly Limit-Exposure levels of penetrating radiation to the whole body or certain critical organs were not to exceed 3 rem per calendar quarter. The calendar quarter referred to specific periods of approximately 13 weeks: January through March, April through June, July through September, and October through December. This quarterly limit was allowed provided the annual exposure limit was not exceeded.

b. Yearly Limit-Exposures of penetrating radiation to the whole body or certain critical organs were not to exceed 5 rem per calendar year.

c. Bettis Control Points-Control points of $1.25 \mathrm{rem}$ per calendar quarter and 3 rem per calendar year for exposures of penetrating radiation to the whole body or certain critical organs were established as an effective means to further minimize personnel radiation exposure below the preceding quarterly and yearly limits. It was required that an assessment of the individual's exposure history be made and that a written approval be received from Radiological Control** management prior to any individual exceeding these control points. (In actual implementation of this requirement, no requests to exceed these control points were required during LWBR core manufacturing.)

\section{Exposure to the Skin of the Whole Body}

Exposures of radiation to unlimited areas of the skin of the whole body were not to exceed $3.75 \mathrm{rem}$ per calendar quarter or $15 \mathrm{rem}$ per calendar year. The increased allowance of these limits over those of Item l above was permitted to account for radiation of low penetrating power that affects only the skin, such as betas and low-energy (less than 0.1 Mev) gammas. (Actual exposures experienced during LWBR core manufacturing were far below these levels.)

\section{Exposure to the Extremities and Other Organs}

Exposures of radiation to the forearms were not to exceed $7.5 \mathrm{rem}$ per calendar quarter or $30 \mathrm{rem}$ per calendar year. Exposures of radiation to the hands, feet, or ankles were limited to $18.75 \mathrm{rem}$ per calendar quarter or 75 rem per calendar year. These higher allowances for the extremities were applicable to belds, gammas, and neutrons of any energy. However, personnel were instructed that

\footnotetext{
*These organs were the head and trunk. gonads. lenses of the eye. and active blood-forming organs (primarily the bone marrowl.

** Radiological Control provided radiological control engineering support and monitoring and surveillance of radiological operations.
} 
every reasonable effort should be made to limit radiation exposures to the forearms, hands, feet, or ankles to the limits of Item 2 above. (Actual exposures experienced during LWBR core manufacturing were far below these levels-see Section VII.B.)

\section{On-Site Uncontrolled Area Exposure Rates}

The maximum exposure rates in on-site uncontrolled areas adjacent to LWBR facilities were not to exceed $0.5 \mathrm{mrem} / \mathrm{hr}$ at the wall and $0.25 \mathrm{mrem} / \mathrm{hr}$ in the general areas. At these exposure rates, monitoring of personnel was not required as they provided less exposure than that allowed to the general public.

\section{Contamination Control Limits}

\section{Airborne Radioactivity Concentration Guides}

Typical Bettis Concentration Guides* and stack discharge concentrations for particulate radioactive materials in air in controlled areas that were applied to the LWBR core manufacturing areas are listed below. These are Concentration Guides for uncontrolled areas for the general public taken from Reference 1 and were used for conservatism as controlled area Concentration Guides by Bettis Laboratory. Control of airborne particulate radioactivity was necessary to limit the internal radiation exposures that can result from inhalation or absorption of radioactive materials.

\section{Concentration Guides and} Stack Discharge

\section{Radioisotope Concentrations $(\mu \mathrm{Ci} / \mathrm{ml}) \dagger$}

Natural thorium

$\begin{array}{ll}\text { Soluble } & 1 \times 10^{-12} \\ \text { Insolublef } & 1 \times 10^{-12}\end{array}$

Uranium-233

$\begin{array}{ll}\text { Soluble } & 2 \times 10^{-11} \\ \text { Insoluble } & 4 \times 10^{-12}\end{array}$

It was required that personnel wear respiratory protection in any area where the airborne radiuac= tivity exceeded or was anticipated to exceed the
Bettis Concentration Guides. Routine use of respiratory equipment was not an acceptable alternate to adequate engineering controls. Full-face respirators were to be used when the airborne radioactivity might reach the Concentration Guide and/or when facial contamination could occur. For areas with high levels of lonse contamination and expected airborne radioaclivity, such as maintc nance on internally contaminated heavy equipment in tent containments, full-face respirators with supplied air were to be used for all personnel entries.

Exposures of personnel to airborne radioactivity exceeding the Concentration Guides above without proper respiratory protective equipment was classed as a radiological control incident which required an investigation of the cause and completion of corrective actions. In addition, involved personnel were to be given a bioassay analysis (i.e., fecal/urine analyses and/or lung scan) to assess whether or not there had been any internally deposited radioactivity.

\section{Surface Contamination Limits}

The limits for surface contamination in clean or uncontrolled areas and controlled surface contamination areas that were applied to the LWBR core manufacturing areas were as follows:

\begin{tabular}{|c|c|c|}
\hline Clean Areas & Alpha & Beta-Gamma \\
\hline $\begin{array}{l}\text { Loose contamina- } \\
\text { tion }\end{array}$ & Nondetectable** & $450 \mathrm{pCi} / 100 \mathrm{~cm}^{2}$ \\
\hline Fixed contaminalion & Nondelectable** & $\begin{array}{l}\text { Radiation level of } \\
0.1 \mathrm{mrem} / \mathrm{hr} \text { as } \\
\text { measured at l incht }\end{array}$ \\
\hline $\begin{array}{c}\text { Conntrolled } \\
\text { Surface } \\
\text { Contamination } \\
\text { Areas } \\
\end{array}$ & Alpháa & Beta-Gamma \\
\hline $\begin{array}{l}\text { Loose contamina- } \\
\text { tinn }\end{array}$ & $50 \mathrm{pCi} / 100 \mathrm{~cm}^{2}$ & $1000 \mathrm{pCi} / 100 \mathrm{~cm}^{2}$ \\
\hline Fixed contamination & No limit & $\begin{array}{l}\text { Posted it radiation } \\
\text { level greater than } \\
1.0 \mathrm{mrem} / \mathrm{hr} \text { at } \\
\mathrm{l} \text { inch }\end{array}$ \\
\hline
\end{tabular}

Entrances to controlled surface contamination areas were conspicuously posted with signs and access restrictione. The r tyuisenisints for anticon. tamination clothing and respiratory equipment

\footnotetext{
* These Concentration Guides were the airborne radioactivity concentration limits established for specific isotopes for Bettis Laboratory operations.

+These were nonoccupational exposure guides for the general public taken from Reference 1 and are $u$ sed for conservatism as occupational exposure limits for Bettis Laboratory operations.

$¥$ This thorium concentration guide was used for control in all fuel manufacturing areas because it is the most conservative concentration for thorium in Reference 1 .

** Using approved survey instruments and smear techniques. The instruments had a sensitivity for detecting less than 50 picocuries alpha and less than 450 picocuries beta-gamma. respectively.
} 
were posted on or alongside these signs. Controlled surface contamination areas were isolated by the use of physical barriers such as walls or rope to mark the affected area clearly. Access to a controlled surface contamination area was limited to personnel in appropriate anti-contamination clothing only.

These controlled surface contamination area limits did not apply to special operations where high levels of contamination were anticipated and special controls were used. Examples of these special operations were operations inside small containment areas such as glove bags, gloveboxes, or enclosures where surface and airborne activity was controlled by a local exhaust system.

To emphasize the importance of preventing the uncontrolled release and spread of contamination, any occurrences which resulted in personnel skin contamination, the unexpected contamination of a surface, a radioactive spill in a controlled area which required more than 4 hours to clean up, or an airborne release greater than the limits specified above or in Section $C$ were classed as radiological control incidents. An incident required a timely investigation of the cause of the incident and completion of corrective actions to minimize recurrence.

\section{Radioactive Liquid Waste}

Annual goals were established to limit the total radioactivity of processed radioactive liquid waste to levels as low as practicable. Control of liquid effluents from the LWBR fuel processing areas was maintained by requiring that all process liquids which came in contact with unclad fuel be placed in nuclearly safe containers and assayed for fissile fuel content. The liquid effluents were then evaporated and/or solidified, packaged, and shipped as radioactive solids to an authorized burial or storage facility. Liquids potentially or slightly contaminated above the acceptable limit were treated in filtration/ion exchange processing systems to reduce the contamination level below acceptable discharge limits.

\section{Radioactive Solid Waste}

It was required that all radioactive solid waste be disposed of through organizations authorized or licensed by the United States Energy Research and Development Administration or Nuclear Regulatory Commissiun. Shipments of radioactive solid wastes were required to conform to the applicable federal regulations.

\section{Controlled Áreas}

\section{Introduction}

Several types of radiologically controlled areas were utilized in the LWBR core manufacturing areas dependent on the materials being handled. In general, a controlled area was defined as an area in which the exposure of personnel to radiation or radioactive materials was controlled and was under the supervision of a knowledgeable individual who had the responsibility for applying the radiological controls appropriate for that area. The necessity for these controls was based either exclusively on radiation, contamination, or airborne radioactivity levels, on a combination of these or on the potential for these conditions to develop. A controlled area could be operated as a - clean area or as a controlled surface contamination area. (See the loose contamination limits of Section C.2.)

\section{Restrictions on Controlled Arreas}

All controlled areas had to be surrounded by a physical barrier (e.g., room walls or rope barricade) and were posted as described in the following paragraphs. If a physical barrier was impracticable (e.g., a chemistry hood operated as a controlled surface contamination area), alternative controls were to be instituted as necessary to prevent inadvertent entry of personnel to the controlled area.

Personnel entering controlled areas (except radioactive materials areas) were required to be qualified Radiation Workers* or to be escorted by a qualified Radiation Worker. Access to controlled areas was restricted by area management to allow only those personnel with the proper protective equipment and radiological training to enter. Entrances to controlled areas were conspicuously posted with signs stating the access restrictions and any anticontamination clothing or respiratory protection requirements for entry. All posted signs were signed and dated when they were erected and were periodically reviewed to ensure that the posting was proper. If the controlled area entrance was not at a door or other well-defined point, barriers were erected and entrance/exit point(s) indicated.

Physical preparation of a controlled area (e.g., erection of barriers) was performed by local area

\footnotetext{
* A qualified Radiation Worker was trained in the requirements of the radiological control manuals and procedures applicable to his work area and was qualified by satisfactory written examinations and personal demonstrations. (See Section IV.C.)
} 
personnel, but the radiological controls were required to be approved and the area posted by Radiological Control prior to use of the area as a controlled area. In those controlled areas where radiation levels frequently changed (e.g., due to movement of fuel modules), Radiological Control delegated to local area management the responsibility for posting as required by ltems 3.a and 3.b below.

\section{Controlled Area Limits}

The following limits were used to define various controlled areas and were posted accordingly.

a. High Radiation Areas-Accessible areas where a major portion of the body or critical organ rould receive a radiation level in excess of $100 \mathrm{mrem}$ in 1 hour. High radiation areas were posted with yellow and magenta signs and were locked nr guarded when nut occupied. Hositive controls were established for each individual entry into a high radiation area and in such a way that no individual was prevented from leaving the high radiation area. Prior to locking an unoccupied high radiation area, the area was required to be inspected to ensure that no personnel remained inside. Each person entering a high radiation area was required to wear a dosimetry badge and pocket dosimeter and to know (approximately) the radiation levels in the area. No loitering or entry by unauthorized personnel was allowed.

b. Radiation Area-Accessible areas where a major portion of the body or critical organ could receive a radiation level between $1 \mathrm{mrem}$ and $100 \mathrm{mrem}$ in 1 hour. Radiation areas were posted with yellow and magenta signs. Yersonnel enterıng such areas were required to wear a dosimetry (TLD) badge. It a person entered a radiation area without a dosimetry badge, this was considered a radiological control incident.

r Radinastiuie Materials Area-Accessible areas where radioactive materials were stored and/or handled, but where the whole body radiation level did not exceed 1 mrem in 1 hour. Radioactive materials areas were posted using yellow and magenta signs

d. Controlled Surface Contamination Area-Controlled areas in which radioactive contamination was present as described in Section C.2. Controlled surface contamination areas were posted with yellow and magenta signs.

e. Airborne Radioactivity Area-Controlled areas in which airborne radioactivity was present in excess of the limits in Section C.I. These areas were posted with yellow and magenta signs and respiratory protection (see Section C.1.) was required for entry.

\section{f. Internally Cunlaminated, Externally Clean} Area-Examples of such areas included gloveboxes, internally contaminated fuel storage vaults with clean vault doors, and internally contaminated equipment with no potential for contamination spread. These areas were posted with yellow and magenta signs. Before opening or entering such an area, the controls for a controlled surface contamination area were required to be established.

g. Other Controlled Áreas-Areas which did not meet the criteria for radiological control given in the paragraphs above but which wese cuul tollet because of the potential for radiological problems to develup (e.y., a yluvebur line operated in a clean area). Necessary radiológical contruls fur such areas, consistent with the potential for a radioloyical problem to vecur, were devoloped and posted on a case basis by area management and approved by Radiological Control.

\section{Radiological Work Permit}

A Radiological Work Permit (RWP) was required for personnel not assigned to a controlled area to do work in the area. The Radiological Work Permit was used to delineate conditions and protective measures to prevent inadvertent exposure of personnel to radiation and/or radioactive contamination. If the work was of a complex nature and involved more than ruuline radiological work praclice, a delailed radiological work procedure, approved by Radiological Control, was required in addition to the RWP. The RWP listed the radiological conditions associated with the work to he performed and the protective measures required by personnel entering the designated area (including the use of anticontamination clothing). The RWP's were to be approved by àrea supervislun dild $\mathrm{R}$ diological Control at the start of edch work shift.

\section{PROGRAM OUTLINE}

\section{A. Introduction}

The radiological control program for the LWBR core manufacturing program encompassed radiological control limits presented in Section III and the specific criteria for meeting these objectives as listed in Sertion B below. These controls were promulgated through the use of radiological control operating procedures, and the training and qualification of personnel in the requirements of these 
procedures. Personnel working with radioactive materials were protected, where required, by the use of radiation shielding, radioactive material containments, and protective clothing. Personnel radiation exposures were monitored by dosimetry devices. Area and environmental control was monitored using radiation measuring instruments. Surveillance of radiological work practices was provided by management personnel, Radiological Control, and special groups to ensure that radiological safety requirements were being met. $\AA$ special group was established within the LWBR core manufacturing organization to work only on problems associated with improving radioactive contamination control and reducing persunnel radiation exposures. The following sections describe these various aspects of the implementation of the radiological control program.

\section{B. General Criteria}

\section{External Exposure Control Criteria}

The external exposure control criteria established for the operation of the LWBR manufacturing facilities were:

a. Total personnel radiation exposure should be minimized.

b. Individual exposures should be minimized and in no case should exceed the limits of Section III.B.

c. The maximum radiation levels in on-site uncontrolled areas adjacent to LWBR facilities should not exceed $0.5 \mathrm{mrem} / \mathrm{hr}$ at the wall and $0.25 \mathrm{mrem} / \mathrm{hr}$ in the general areas.

To aid in satisfying the above criteria, maximum practicable shielding was designed into the facilities and process equipment. To minimize total personnel radiation exposure, the effect of personnel rotation out of manufacturing operations was not included in establishing shielding requirements and designs.

\section{Contamination Control Criteria}

The intent of the contamination controls for the LWBR fuel manufacturing facilities was to minimize the release and spread of contamination and to prevent personnel from receiving internal or external depositions of radioactive materials. The following general control methods were recognized in the design of the fuel facilities and were utilized in the operation of the facilities:

a. Minimizing the areas which could become contaminated by use of local and secondary containment b. Confining accidental contamination within small areas and by controlling movement of personnel into and out of these areas

c. Routinely cleaning and monitoring the interior of the primary containment boxes to maintain contamination levels within the boxes as low as practicable

d. Preventing contamination of personnel by use of appropriate protective equipment and work clothing

e. Monitoring and controlling the activity in liquid and gaseous wastes

f. Taking special precautions for the disposal of radioactive solid wastes.

Complete containment of the ${ }^{233} \mathrm{U}$ binary fuels was the primary objective; therefore both high integrity primary containment systems and an area secondary containment design were utilized throughout the binary fuel manufacturing operations. Surface contamination in all the LWBR facilities except the Ceramic Processing Facility* was controlled and maintained below the Bettis limits for clean areas as specified in Section III.C.2. Airborne radioactivity levels in work areas were controlled below the applicable Bettis limits for occupational exposure and unrestricted release as specified in Section III.C.I.

\section{Radiological Control Procedures}

Operating procedures containing radiological control requirements were developed for each manufacturing area and were required to be followed in all work involving radioactive materials. These procedures provided a vehicle for training personnel in the radiological controls required to perform their assigned duties in a safe and knowledgeable manner.

Nonroutine procedures, primarily maintenance and repair procedures, were developed on a case basis. All procedures involving radiological control required Radiological Control review and approval of their radiological satety requirements.

The procurement of equipment, modification of facilities, or development of new facilities for handling radioactive materials required review and approval by the Radiological Control for appropriate radiological and other safety considerations before procurement or modification action was initiated.

\section{Training}

Training each person involved in the manufacture of LWBR fuel and fuel assemblies to carry out his manufacturing duties in a nuclearly safe manner with minimum radiation exposure and minimum release of radioactivity to the environment

* See Section V for a description of this facility 
was mandatory. Therefore, a radiological safety training program was designed and implemented. It consisted of two phases which qualified the trainees to work in LWBR manufacturing facilities.

Phase one involved classroom training on radiological safety fundamentals and their applications in the LWBR fuel manufacturing operations. Topics covered during the classroom phase included radiological control, criticality control, safety, fuel materials management, radioactive waste processing, and fire protection. The length of the classroom phase ranged from 20 to 36 hours.

The training presented during the classroom phase was considered necessary for all personnel to provide them with a good background in fundamentals. This basic knowledge led to a better understanding of the reasons for the radiological safety procedures and controls that were established. which in turn promoted a better attitude toward radiological safety. Passing scores on written questionnaires for each phase of the training were required.

The second phase consisted of the practical experience and qualification of each trainee on the radiological safety aspects of the specific processes, systems, procedures, and practices he was to be associated with in the LWBR manufacturing facilities. It included first-hand, in-shop observation, experience, and participation in drills for radiological control problems, and individual checkouts and discussions of radiological control aspects of the operations with qualified and knowledgeable personnel. Formal signoffs were required for specific practical factors, i.e. personnel demonstrations. Oral and written examinations were required for fuel shop foreman, radiological control technicians, and fuel vault custodians. The trainee completed this phase of training in a period of 2 to 3 weeks on a part-time basis.

To maintain personnel knowledge of radiological safety at a satisfactory level, a continuing program of training was established. It was based primarily on periodic classes or workplace meetings emphasizing (1) review of radiological safety fundamentals and their application to the specific rules and procedures established for the personnel's assigned work areas, (2) changes to procedures, and ( 3 ) radiological safety problems as they arose and the corrective actions taken. In addition, radiological safety drills were carried out periodically to measure the performance of the personnel involved. Personnel working in LWBR manufacturing facilities were required to be formally requalified at least every 2 years.

\section{E. LWBR Core Radiological Sur- veillance Program}

A comprehensive radiological surveillance program was established as an integral part of the LWBR core radiological control program. This surveilance program (see Appendix A) included monitoring and surveys as required to confirm compliance with the radiological controls and limits specified in the radiological control documents and to provide sufficient early identification of the potential loss of controls to preclude exceeding the appropriate limits or control guides. This surveillance program was carried out routinely by Radiological Control personnel and was supplemented by surveillances by management and the special group established to work on contamination control and radiation exposure problems.

\section{F. Radiation Exposure Control Pro- gram}

\section{Monitoring}

The radiation exposure control program was based on a comprehensive monitnring program to provide prompt identification and evaluation of radiation exposure data plus the institution of timely corrective actions. To monitor exposures effectively, both personnel and areas were monitored. Both Radiological Control personnel and LWBR management evaluated the data and instituted corrective actions as required.

a. Personnel Monitoring--All personnel were monitored for whole-body and skin exposures using lithium fluoride thermoluminescent dosimeters (LiF TLD), mounted in badges, utilizing a mylar covered open window and a window with a 50 mil cadmium shield. The TLD badges were processed monthly. Initially all fuel processing technicians were monitored for extremily exposures using LiF TLD chips in ring badges. After significant data were accumulated and evaluated, it was determined that extremity monitors were not required for most operations, as radiation exposures were less than 10 percent of that required to approach the extremity limits of Section III.B.3. However, ring badges were issued to selected operating personnel whose extremity exposures would be representative of the various operator assignments involving contact handling of fuel materials. 
Neutron film in the badges was employed for processors who operated assay gauges which used an isotopic neutron source.

All personnel assigned routine duties in areas handling unclad ${ }^{233} \mathrm{UO}_{2}$ or $\mathrm{ThO}_{2}$ were included in the internal exposure monitoring program described in Appendix A.

In special cases, where a technician's body would be shielded but not his arms, TLD chips in polyethylene packets were attached to various locations on his arms to establish if such monitoring would be required. It was determined that in no case was continuous arm monitoring required, as radiation exposures were less than the monitoring criteria in Reference l. In a like manner, TLD chips under head bands were used to monitor eyes, and in no case was continuous monitoring required.

All fuel processing technicians were required to wear 200 mrem full-scale, self-indicating pocket dosimeters. These dosimeters were to be read by the individual at least at the start of the shift, at lunch break, and at the end of the shift. When a pocket dosimeter reached values between 100 and $150 \mathrm{mrem}$, it was rezeroed by Radiological Control. The radiation exposure from the pocket dosimeter at the time of rezeroing was logged and added to the accumulated exposure from the TLD readings; thus, a running total exposure was maintained for each person during the month, prior to processing the TLD at the end of the month.

A type of personnel monitoring that was not for record purposes but which had very effective results was the use of audible dosimeters. Various personnel were issued audible dosimeters on a temporary basis to wear during their work cycles. The audible rate emphasized to them the exact locations of the higher radiation fields within their work areas and resulted in improved work habits, thereby lowering personnel radiation exposures

b. Area Monitoring-Routine surveys were performed by Radiological Control to identify the Eources of radialiun fields and any changes in these fields. These surveys were used to establish radiation areas of less than $0.5 \mathrm{mrem} / \mathrm{hr}$, which were marked by tape on the floor and used by operating personnel to identify low exposure areas for use when walking between areas, holding discussions, taking a break, or processing paperwork. They also provided a basis for the design and installation of additional shielding.

Continuous gamma monitors and TLD area monitors were distributed in various fuel processing and assembly areas where significant radiation levels could be encountered. They were utilized to observe any significant changes in the radiation fields within an area.

\section{Rem Reduction Program}

The objective of the Rem Reduction Program was to further minimize the tolal radiation exposure received by all personnel as well as individual exposures. Several actions were taken to accomplish this objective. In addition to the installation of more shielding and shielded facilities, rem reduction actions taken included the establishment of the following:

1. An annual personnel radiation exposure goal for LWBR core manufacturing

2. Group radiation exposure goals

3. Additional personnel training programs

4. Job radiation exposure limits

5. A radiation exposure alert system

6. Work practice surveillances by management and special groups.

a. Total Exposure-At the start of each year a rem goal was established. This goal applied to all groups involved in manufacturing the LWBR core and included a significant reduction ( 10 to 15 percent) from the previous exposure or projected exposures for new operations. Senior management attention was focused on meeting this goal. The overall annual goal was established by totalling the individual goals established for the various manufacturing or inspection groups. Meeting the goal required attention to all exposure levels, as the sum total of small exposures of the bulk of the personnel could account for more total exposure than the relatively few higher exposures.

b. Maximum Individual Exposures-It was judged that the LWBR core could be fabricated without personnel radiation exposures approaching the limits of References 1 and 2. As a rem reduction action, control points of 1.25 rem per quarter and 3 rem per year were established which were not to be exceeded without the approval of the Manager of Radiological Control. No one was allowed to exceed these control points and, in fact, very few persons (less than 15 out of a total of about 600) approached the 3 rem per year control point during the $31 / 2$ years of core manufacturing operations.

A radiation exposure Alert System was implemented with the objective of notifying an individual and his immediate supervisor when radiation exposure control points were being approached. When an individual's current quarterly exposure reached 1000 mrem as determined from pocket dosimeter and TLD badge readings, his badge was processed. His name was placed on the Alert List, and he and his management were informed 
promptly of the accumulated exposure. Subsequently during the quarter, the badge was processed at intervals of at least 50 mrem as determined from the pocket dosimeter. Additional exposure was not normally allowed after reaching 1200 mrem as determined by the dosimetry badge. A similar procedure was implemented when the calendar year exposure reached 2750 mrem.

\section{Management Control}

To aid first line management in controlling personnel radiation exposures, the results of area radiation surveys and the TLD badge readouts for all personnel reporting to them were sent to them as soon as possible. The TLD badge result sheets included a statement of the rem goal for the particular group. These results were evaluated by management to observe overall trends and individual personnel exposures that were out of line so that corrective actions could be initiated. Additionally, a monthly evaluation report of exposures was issued to IWBR senior management which listed the radiation exposures of each individual by job type and evaluated the exposure trends associating them with production output and the actions taken to reduce exposure. These aids were augmented by surveillances of work practices by LWBR management, the special LWBR group for radiation and contamination control, and Radiological Control technicians and engineers. These surveillances provided a basis for recommendations for improved rem reduction through facility and procedure modifications and improved work practices.

From these sources as well as their own personal observations, first line management was able to take or initiate actions to reduce personnel exposure, and they received strong support from senior management in these areas. The methods used by first line management consisted primarily of initiating action to improve shielding and to improve work practices through workplace training meetings and correction of individual actions. Significant shielding modifications and procedural changes were made as a result of evaluations by manufacturing and facility engineers, the special LWBR gromp, and Radiological Control engineers.

\section{DETAILED DESCRIPTION AND OPERATIONAL EXPERIENCE}

\section{A. Introduction}

As noted in Section II, large quantities of ${ }^{233} \mathrm{U}$ and ${ }^{232} \mathrm{Th}$ were handled in both clad and unclad form during LWBR fuel manufacturing and module assembly. This presented a significant potential for contamination during manufacturing operations with unclad fuel materials and for high radiation fields during operations with both clad and unclad binary fuel material. For these reasons, radiological controls were applied to the design and operation of the LWBR fuel and fuel rod facilities to minimize personnel exposure to radiation and radioactive materials. Since the radiation levels for binary fuel increased with time to a maximum at about 3000 days or -10 years (see Figure 1), a conservative but practicable fuel age limit was estahlished for the various manufacturing phases, such as powder processing and pellet processing, rod loading, rod inspections, and module assembly. (The shield design basis and personnel exposure estimates are discussed in Appendix B.)

Figure 2 is a process flow chart showing operations in the three main LWBR core manufacturing facilities: the Ceramic Processing Facility (divided between areas designated W5L N-Building and the RA-Building), the Binary Development Area, and the Fuel Rod Facility (divided between areas designated the BC Aisle and the Core Module Assembly Area (CMAA)). Thoria powder was processed into thoria pellets and the pellets inspected in the Ceramic Processing Facility. Urania and thoria powders were processed into binary pellets, the pellets were inspected, and the thoria and binary pellets were loaded into tubes to form fuel rods in the Binary Development Area. The fuel rods were inspected and assembled into fuel modules in the Fuel Rod Facility. A summary description of the facilities' inenufacturing operations, the application of radiological control procram objectives, and the recults for earh if the three main facilities is presented below.

\section{B. Ceramic Processing Facility}

\section{Introduction}

The Ceramic Processing Faoility included two separate facilities that were utilized for the processing of the thoria powder and pellets. One facility (W5L N-Building) was operated as a controlled surface contamination area. This designation was based upon previous experience in processing thoria materials and the economy of processing thoria in an existing facility. In this facility, all the processing was performed starting with the thoria powder as received from the vendor and ending with centerless ground, sintered pellets.

The low specific activily of $\mathrm{ThO}_{2}$ permitted its processing to be carried out in equipment installed in hoods or exhausted enclosures. To prevent spreading loose, low-level activity to clean or 


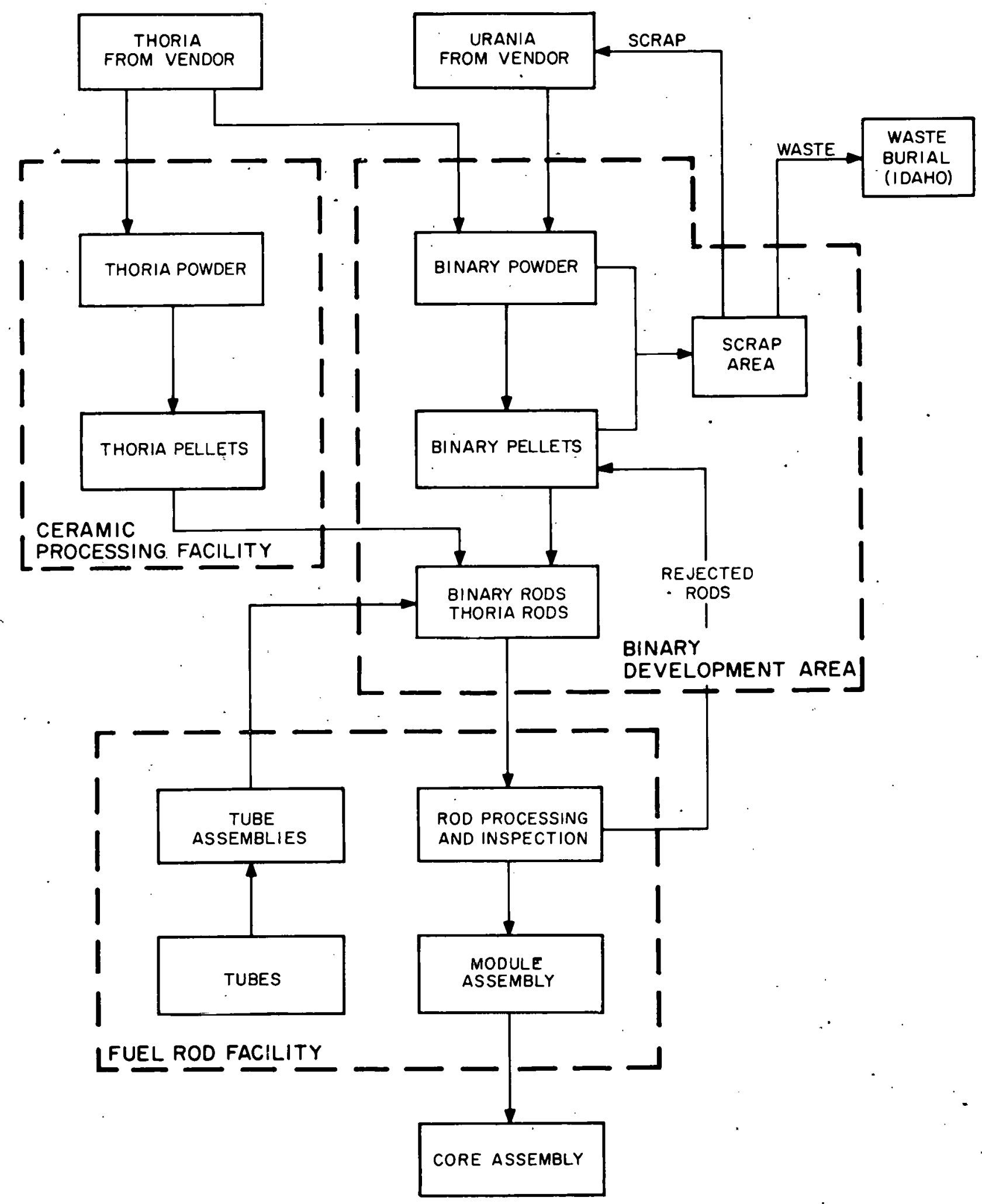

Figure 2. LWBR Core Manufacturing Process Flow Chart 
uncontrolled areas, access to the controlled surface contamination area was restricted to those personnel with proper protective equipment. The proper protective equipment for manufacturing personnel was anticontamination coveralls, gloves, and shoes. Removal of anticontamination clothing was required before leaving the controlled area. $\mathbf{A}$ whole-body frisk with an alpha survey instrument was required to verify that the person was free of alpha activity $\left(<50 \mathrm{pCi} / 50 \mathrm{~cm}^{2}\right)$ upon leaving the area. Materials to be removed from the area were monitored (frisked), and those determined to be contaminated were properly contained in sealed yellow polyethylene bags or sheets.

The other facility (RA Building) was operated as a controlled, radiologically clean area. In this facility the finished pellets were inspected before they were sent to the rod loading line. These inspections were accomplished in controlled surfaoo contamination hoods and qloveboxcs, where only the inspectors' hands and arms (with protective covering) entered the containments. Personnel were required to do a whole-body frisk wilh du alpha survey instrument prior to leaving the area.

The potential for receiving high external radiation exposures in the Ceramic Processing Facility was much less than for the Binary Development Area because of the long half-life of ${ }^{232} \mathrm{Th}$ compared to the ${ }^{232} \mathrm{U}$ present with the ${ }^{233} \mathrm{U}$. The principal external radiation exposure problems in the Ceramic Processing Facility were due to accumulations of thoria materials before, during, and after processing. The only shielding utilized was stacked solid concrete block storage areas which were installed as needed in or near the processing points where significant amounts of thoria powder, pellets, or waste were stored.

Typical monthly average personnel exposures for the different Ceramic Processing Facility operations are listed in Appendix C.

\section{Manufacturing Operations}

The Ceramic Processing Facility contained all the necessary manufacturing facilities and required supporting services for processing thorium oxide $\left(\mathrm{ThO}_{2}\right)$ powder into finished thoria pellets. Pollet manufacture involved powder receipt, micronizing, agglomerating, granulating, fractioning, and pressing, followed by pellet bindor removal, sintering, grinding, cleaning, inspection, and storage.

\section{Maintenance and Repair Control}

Radiological control during nonroutine equipment maintenance and repair was maintained by use of written repair procedures which included required radiological controls. Each procedure for the maintenance or repair job was developed by area personnel and subsequently approved by Radiological Control.

Work was performed in the controlled surface contamination area in a manner to minimize the spread of contamination. Containments were used in repair work on systems in controlled surface contamination areas where there was a potential for spreading contamination. For instance, a tent was used to enclose a sintering furnace during replacement of heating elements and fire brick. Tents or PVC plastic enclosure bags were used for replacement of exhaust system high efficiency particulate air (HEPA) filters. Continuous surveillance by Radiological Control was utilized to minimize radiation and contamination exposure during these operations.

\section{Vertilation System}

An exhaust system with a design capture velocity of at least $100 \mathrm{fpm}$ for all equipment enclosures and hoods in the manutacturing dud pellent inspec tion areas was utilized, except that the minimum capture velocity for centerless grinders and $\mathrm{mi}$ cronizers was $150 \mathrm{fpm}$ where the particulate levels during operation were high. The exhaust gases passed through a prefilter and a HEPA filter before being released to the environment. The exhaust gases from the pretreat and sintering furnaces passed through a sludge trap, prefilter, a HEPA filter, and a charcoal filter before being released to the environment. Makeup air for the system was drawn from the environs. All exhaust air and gases were sampled on a continuous basis and routinely monitored for particulate radioactivities as described in Appendix $\bar{A}$.

\section{Liquid and Gaseous Effluent Control}

Control of liquid effluent was maintained by requiring that all liquids which had contacted thoria or which were potentially contaminated be collected. Any liquid collected was either sampled and released if nonradioactive, or transferred to an area where the liquid was processed by solidification, filtration/ion exchange, or by evaporation to remove most of the radioactivity. The water was then analyzed and roleased only if release criteria were met. The use of liquids in the facilities was minimized to minimize the generation of liquid wastes.

Gaseous effluent control was maintained by requiring that all exhaust air streams from operations involving unclad thoria and from controlled surface contamination areas be exhausted through an exhaust system containing HEPA filters and into a stack with an exhaust air sampler. The exhaust air 
was continuously sampled for particulate radioactivity and sampler filters were periodically collected and counted for control purposes and for environmental release reporting. Activated charcoal filters were placed in the exhaust systems into which ${ }^{220} \mathrm{Rn}$ gas was expected to be released by the fuel processing steps. This minimized the release of ${ }^{220} \mathrm{Rn}$ to the environment.

\section{Solid Waste Disposal}

Radioactive contaminated solid waste generated from the thoria facilities was disposed of by sealing it in yellow polyethylene bags. These were then packaged in Department of Transportation approved containers (55-gallon drums) for truck shipment to a Nuclear Regulatory Commission licensed commercial disposal facility.

\section{Area Monitoring and Surveillance}

In addition to the above controls, routine surveys of areas, materials and equipment were conducted by Radiological Control as described in Appen$\operatorname{dix} \bar{A}$.

\section{External and Internal Exposure Monitor- ing}

All personnel assigned routine duties in areas handling unclad thoria were included in the external and internal exposure monitoring program described in Appendix A.

\section{Binary Development Area}

\section{Introduction}

The Binary Development Area was designed and built specifically to contain all manufacturing operations which involved exposed ${ }^{233} \mathrm{U}$ fuel. It was separated from other Bettis activities to minimize the possibility uf cunlaminating other laboratory spaces with ${ }^{233} \mathrm{U}$. The building was designed to minimize the effort involved in decontamination.

The Binary Development Area contained all the necessary manufacturing and inspection facilities and required supporting services for processing unclad binary fuel. Manufacturing operations included: (1) processing uranium oxide $\left({ }^{233} \mathrm{UO}_{2}\right)$ and thorium oxide $\left(\mathrm{ThO}_{2}\right)$ powders into finished binary fuel pellets; (2) loading the binary fuel pellets and thoria pellets into fuel rods; and (3) welding the second enclosure on the fuel rods to encapsulate the fuel. Pellet manufacture involved powder receipt, blending, micronizing, agglomerating, granulating, fractioning, and pressing, followed by pellet binder removal, sintering, grinding, inspection and storage. The equipment layout provided a continuous, sequential material flow through a glovebox line. Space was provided in the building for manufacturing support operations such as quality control, analytical chemistry evaluation, radiological control, and radioactive waste processing control. The various areas were separated by walls and partitions where necessary to maintain local environmental requirements.

\section{Contamination Control}

The Binary Development Area was operated as a clean (noncontaminated) facility. The primary containment was provided by high-integrity containment glovebox systems (Figure 3). Secondary containment was provided by the area partitions (Figure 4) and the building itself as supplemented by the exhaust air handling systems and a local monitoring/control concept.

a. Primary Containment System-All operations with unclad ${ }^{233} \mathrm{U}$ or binary fuel were performed inside gloveboxes. The gloveboxes provided complete enclosure of the fuel and process equipment, and operations were conducted using gloves sealed to the glovebox walls. With few exceptions all gloveboxes were connected by tunnels to provide for a continuous transfer of material throughout the containment enclosures. The glovebox systems in the manufacturing area were operated and maintained at a negative pressure of 0.6 to $\mathrm{l}$ inch $\mathrm{H}_{2} \mathrm{O}$ with respect to the operating areas. Fire protection was afforded by low temperature and high temperature heat detectors in each glovebox. The low temperature units alarmed locally and the high temperature units alarmed through the Central Alarm Panel. Air flow dampers and box isolation permitted manual containment of any fire within a given glovebox or enclosure. Carbon dioxide extinguishing systems were piped into each glovebox. Combustibles contained inside the gloveboxes were kept at a minimum.

All gloveboxes in the manufacturing area were individually equipped with an air exhaust connection with local HEPA filters and prefilters to confine any contamination to the box in which it was generated. Except during fuel or material transfer, individual boxes were isolated by closed doors on each end of the boxes. Routine cleaning of all box interiors was performed to maintain contamination levels within the boxes as low as practicable. Routine radiation surveys of boxes and exhaust ducts were performed by Radiological Control to monitor for contamination buildup in the individual gloveboxes and the exhaust ductwork.

Transfers of material into or out of the glovebox system, with the exception of pellets being loaded 


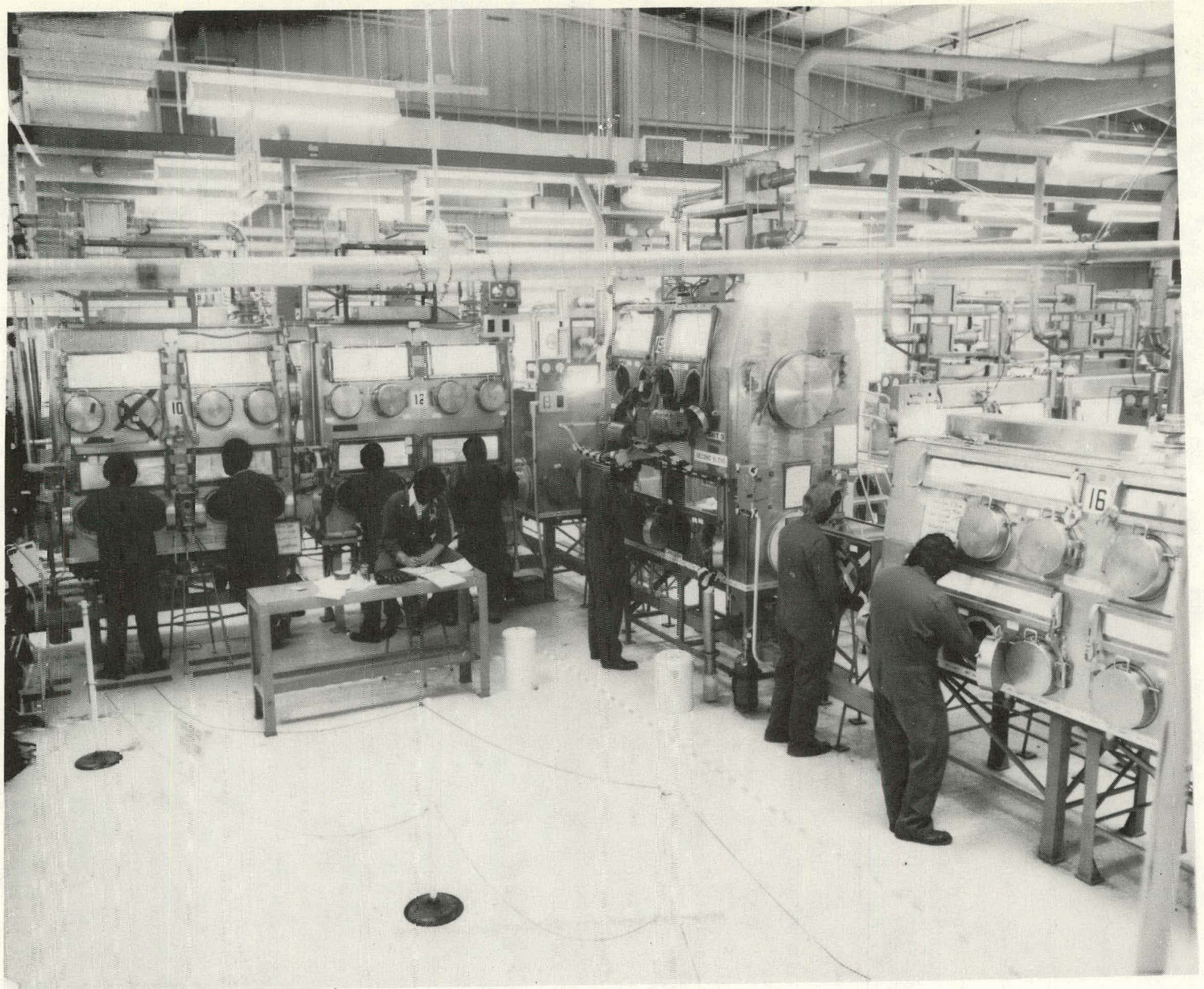

Figure 3. Typical Section of Glovebox Processing Line 


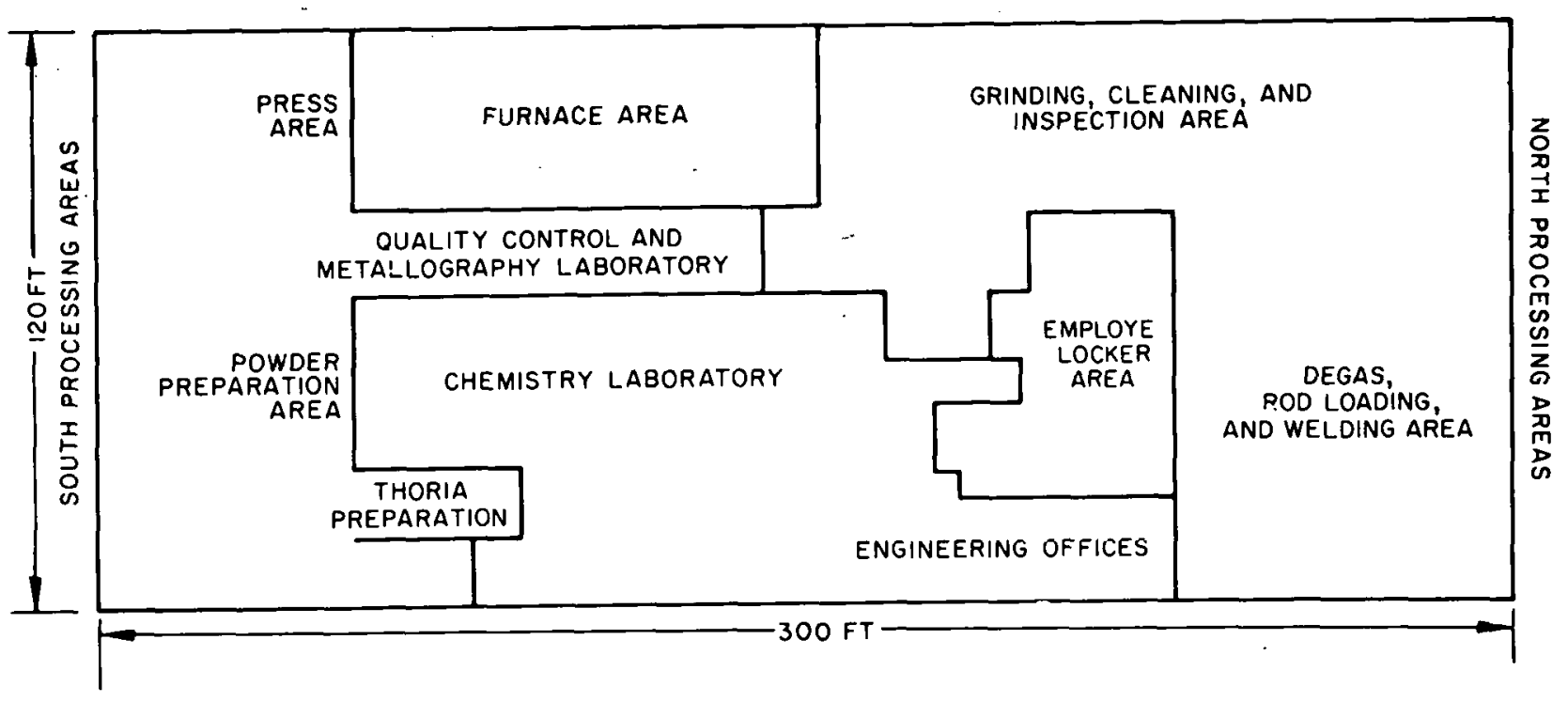

Figure 4. Binary Development Area Layout

into fuel rods, was accomplished by sealing the material in yellow plastic tubing, attached to transfer ports on the glovebox, before making the transfer.

b. Secondary Containment and Area Controls-The Binary Development Area building was a windowless, essentially airtight secondary containment structure. The manufacturing and quality control (metallographic) sections of the building were operated as one large controlled area (Figure 4). Contamination levels outside the glovebox system were maintained below the limits for uncontrolled areas. The chemistry laboratories were also operated as controlled areas with the same restriction on contamination levels. The manufacturing controlled area was maintained at a negative pressure of 0.4 to 0.8 inch $\mathrm{H}_{2} \mathrm{O}$ with respect to the atmosphere and the remainder of the building was maintained at a negative pressure of 0.04 to 0.2 inch $\mathrm{H}_{2} \mathrm{O}$ with respect to the atmosphere. The exhaust and air-handling systems and entry/exit controls for the areas were designed and established such that the controlled areas constituted separate secondary containment areas within the building. Building fire protection was provided by sprinklers located within the building. Smoke detectors, fusible-link dampers, and hydrogen detectors were also installed.

The final control points for the two controlled areas were the frisking stations at the exits from those areas as shown on Figure 5. This figure also shows the boundaries of the controlled areas and planned personnel traffic patterns to and between areas. As shown on the figure, the only access to the building and the manufacturing controlled area was through air locks because of the pressure differential between the areas, building, and atmusphere.

All personnel movement between areas was as shown by the traffic patterns, except in the case of emergency evacuation. Showering and other sanitary facilities were provided at the exit from the manufacturing area. Material and equipment entered or left the manufacturing area through the air locks in the southeast and northeast ends of the building. All material leaving the Binary Development Area was monitored for contamination by Radiological Control or operating personnel.

c. Exhaust and Air Handling Systems-The air handling systems for the Binary Development Area were designed to meet industrial hygiene and personnel comfort requirements, process and quality control requirements, and radiological control requirements. The radiological requirements were. (1) that the systems supplement the primary and secondary containment systems or areas by maintaining the required pressure differentials between the building, controlled areas, glovebox systems, and atmosphere and (2) that all potentially contaminated exhaust from the building and systems be passed through HEPA filtration prior to discharge to the environment.

All exhausts from the containment systems and controlled areas were passed through highefficiency filters and discharged to a common stack. The manufacturing glovebox system and 
(Intentionally Blank) 


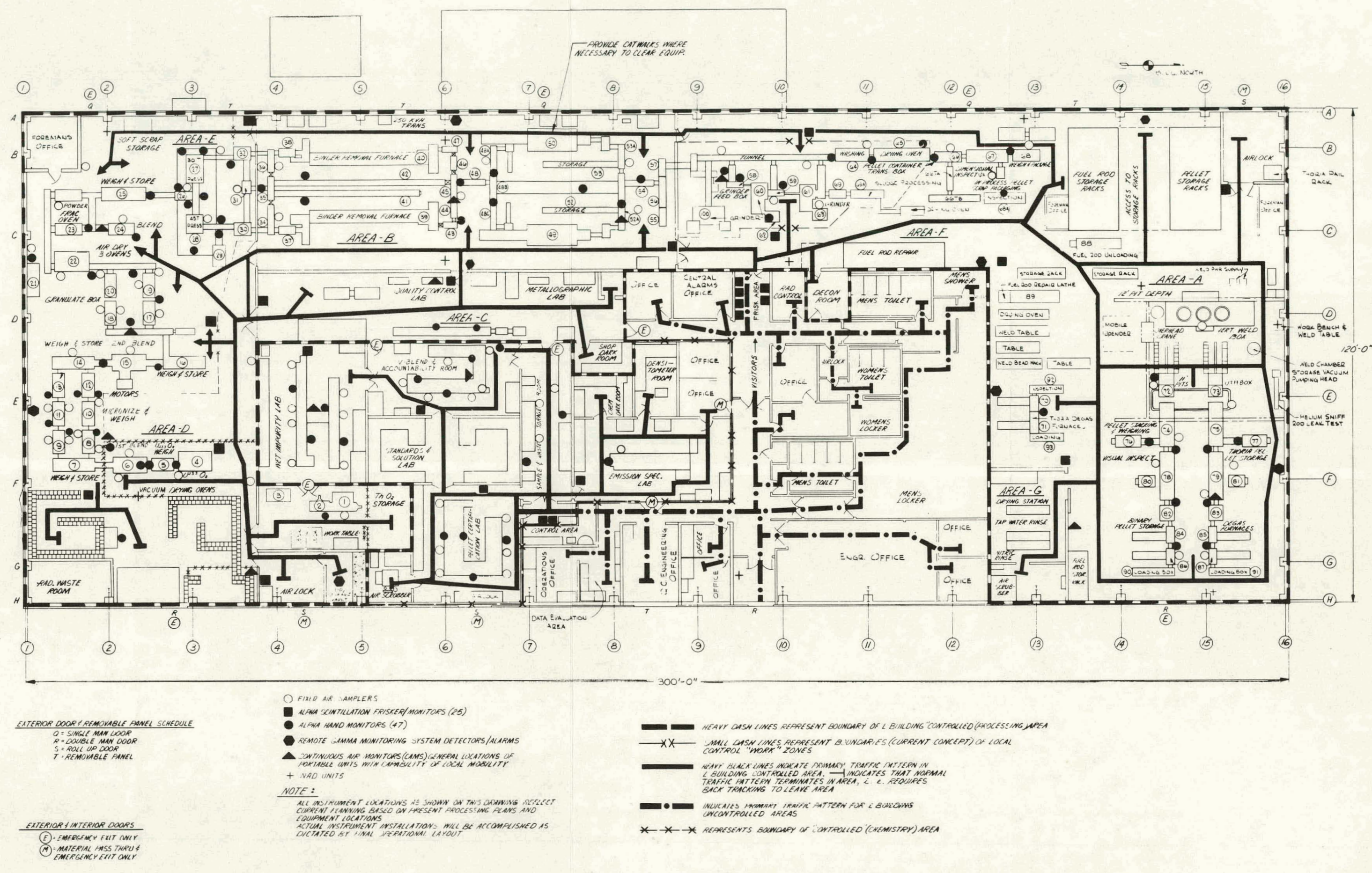

Figure 5. Binary Development Area

Equipment Layout and Traffic Pattern 
uva exhaust were passed through a pretilter and high-efficiency filter at each box and two additional banks of filters in series prior to discharge to the stack. All high-efficiency filters were tested for leakage by the standard dioctalphthalate (DOP) smoke test when installed and were retested annually or when replaced, whichever occurred first.

The various recirculating air conditioning systems were isolated such that no system serviced two different areas of significantly different contamination potentials. All recirculated air in the controlled areas passed through intermediate efficiency filters (75-percent efficiency per National Bureau Standards (NBS) dust spot test) at a minimum rate of three volume changes per hour. The radioactivity levels of the recirculating air from the South Processing Areas, North Processing Areas, and Chemistry area (Figure 4 ) were monitored by continuous air monitors which would initiate an alarm on the Central Alarm Panel in the Central Alarms Office if the airborne activity level limit was approached.

To prevent release and buildup of ${ }^{220} \mathrm{Rn}$ gas in work areas and exhausts, the $\mathrm{CO}_{2}$ binder removal furnaces and hydrogen sintering furnaces were included in the containment system by connecting air locks into the fuel transfer tunnels. The binder removal furnace exhausts were discharged through sludge traps into the glovebox exhaust system. The burn-off gases from the sintering furnace were collected by local hoods at each burnoff port which provided complete capture of the gases and rapid cooling prior to discharge into the glovebox exhaust system. Radon concentrations were not expected to exceed the allowable limit in the final high-volume exhaust stream; however, to ensure that minimal gaseous activity was released, the exhaust from the manufacturing area glovebox systems was also passed through activated charcoal filter beds prior to discharge.

Figure 6 is a photograph of one of the $\mathrm{CO}_{2}$ binder removal furnaces with a hydrogen sintering furnace in the background. The sludge trap condenser followed by prefilters and HEPA filters can be seen to the right of the binder removal furnace sign. A sintering furnace with its local hood for collecting burn-off gases can be seen in the background (upper right on photograph). Figure 7 is a top view photograph of the furnace room taken from the same end of the room as Figure 6. This shows the two furnace lines along with furnace boat storage tunnel gloveboxes in the center of the photograph.

d. Personnel Frisking and Local Contamination Control Concept-When leaving the manufacturing controlled areas all personnel were re- quired to frisk their entire bodies and materıals or equipment being removed for alpha radioactivity contamination and, if not contaminated, proceed to the change areas. If any contamination was detected, personnel were escorted by Radiological Control to the personnel decontamination room after taking appropriate steps to avoid the spread of contamination. Contaminated material or equipment was bagged in clean bags and tagged prior to removal from the area. The locations of the controlled areas, local work zones, frisking stations, other radiological control instruments, and the personnel decontamination room are shown on Figure 5.

Inside the controlled areas, hand contamination (alpha activity) monitors* were located along the glovebox lines such that a monitor was within a few steps of any operating station. The go/no-go hand friskers are shown attached to the storage tunnels in the foreground of Figure 7. Operators used these monitors to frisk their gloved hands after each glovebox operation and before proceeding to another operation or leaving the work area. Within the manufacturing area two local control work zones were established, one around the gloveboxes where powder was processed and one around the pellet grinding boxes. Personnel left those local work zones at specified exit points, as shown on Figure 5, where they were required to frisk their hands, bodies, and feet for contamination. These requirements and the disposition of monitoring equipment in the controlled areas provided early identification of glove leaks or other breaches in the containment and thus allowed correction before contamination could be spread within the manufacturing area.

Some material transfers and occasional rupture of gloves resulted in small amounts of fuel being released from the glovebox line. Under such circumstances, a temporary controlled surface contamination area was established about the local work station as necessary to confine contamination and localize decontamination operations. A change line was established at the entrance/exit point, and personnel entering the area were required to wear anticontamination clothing.

Figure 8 shows a typical local control work zone exit point. The chain barrier was closed except when entering or exiting the area to remind personnel of the area radiological control requirements. The chain barrier entrance and exit was left open in Figure 8 to better define its location in the figure.

e. Airborne and Exhaust Activity Monitoring-Airborne activity levels were continuously evaluated using filter samplers and continuous air

\footnotetext{
* Set to alarm at approximately $50 \mathrm{pCi}$ alpha activity in contact with the detector protective screen.
} 


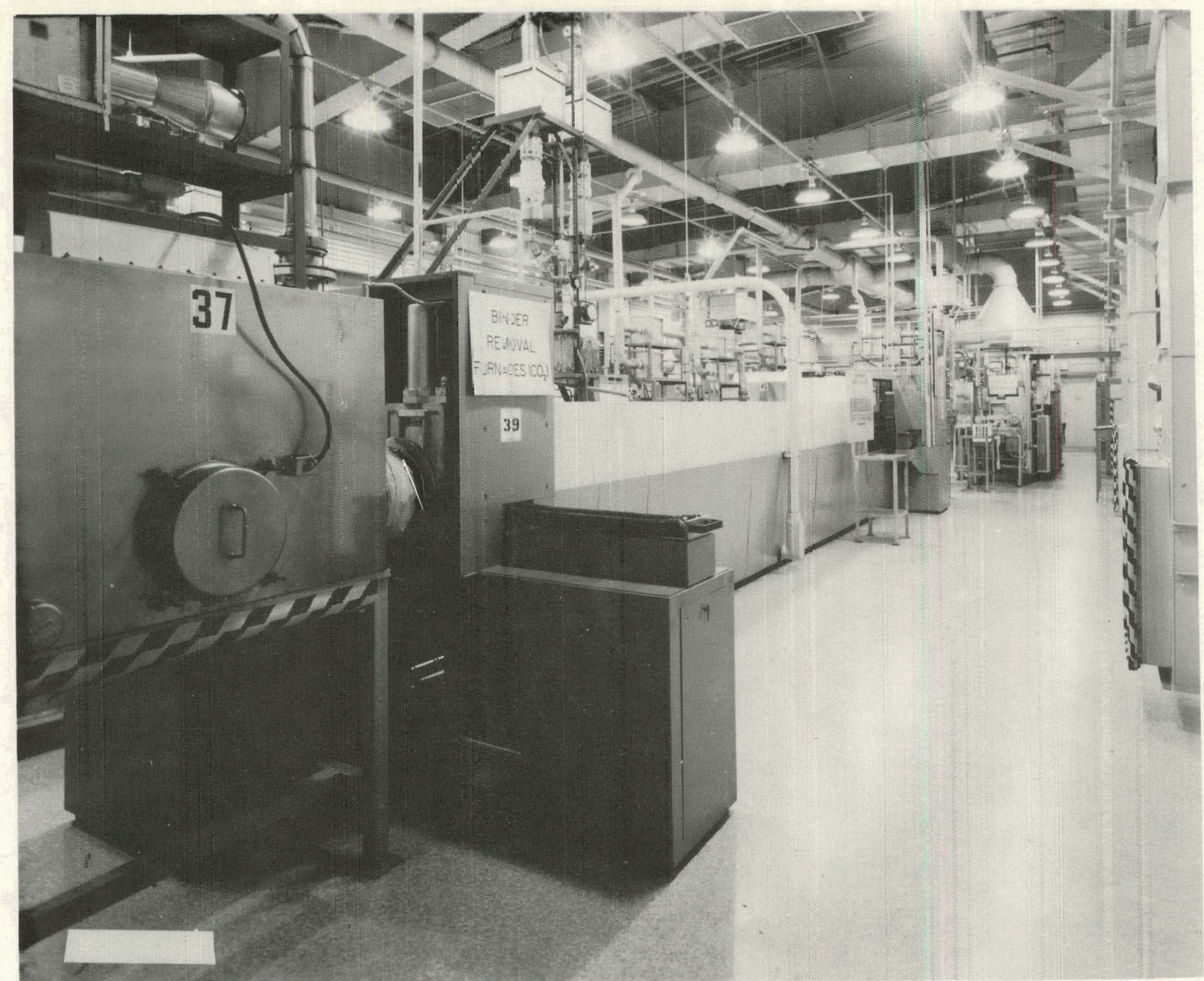

Figure 6. Birary Deve opment Area $\mathrm{CO}_{2}$ Binder Removal Fu-r.ece 


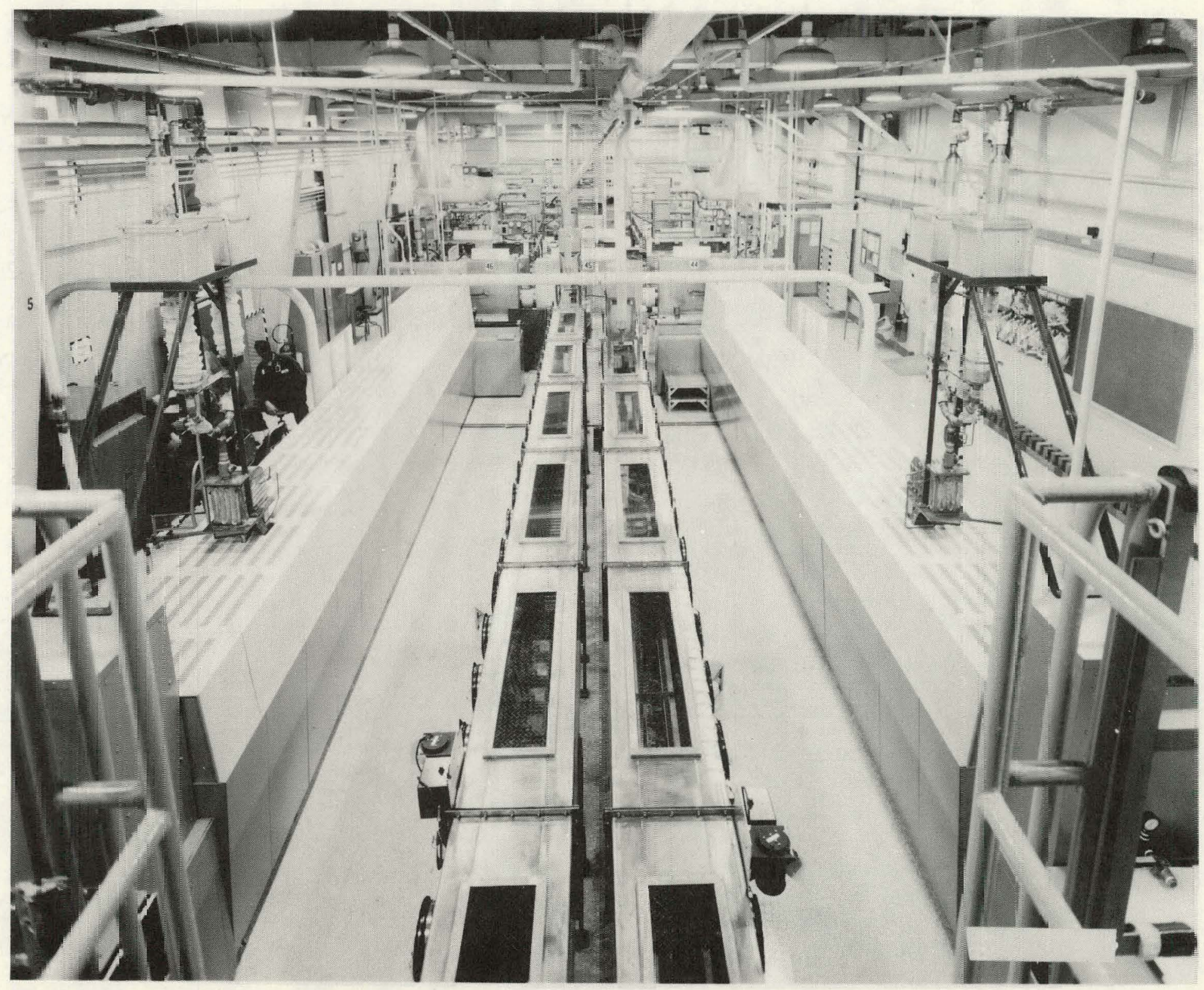




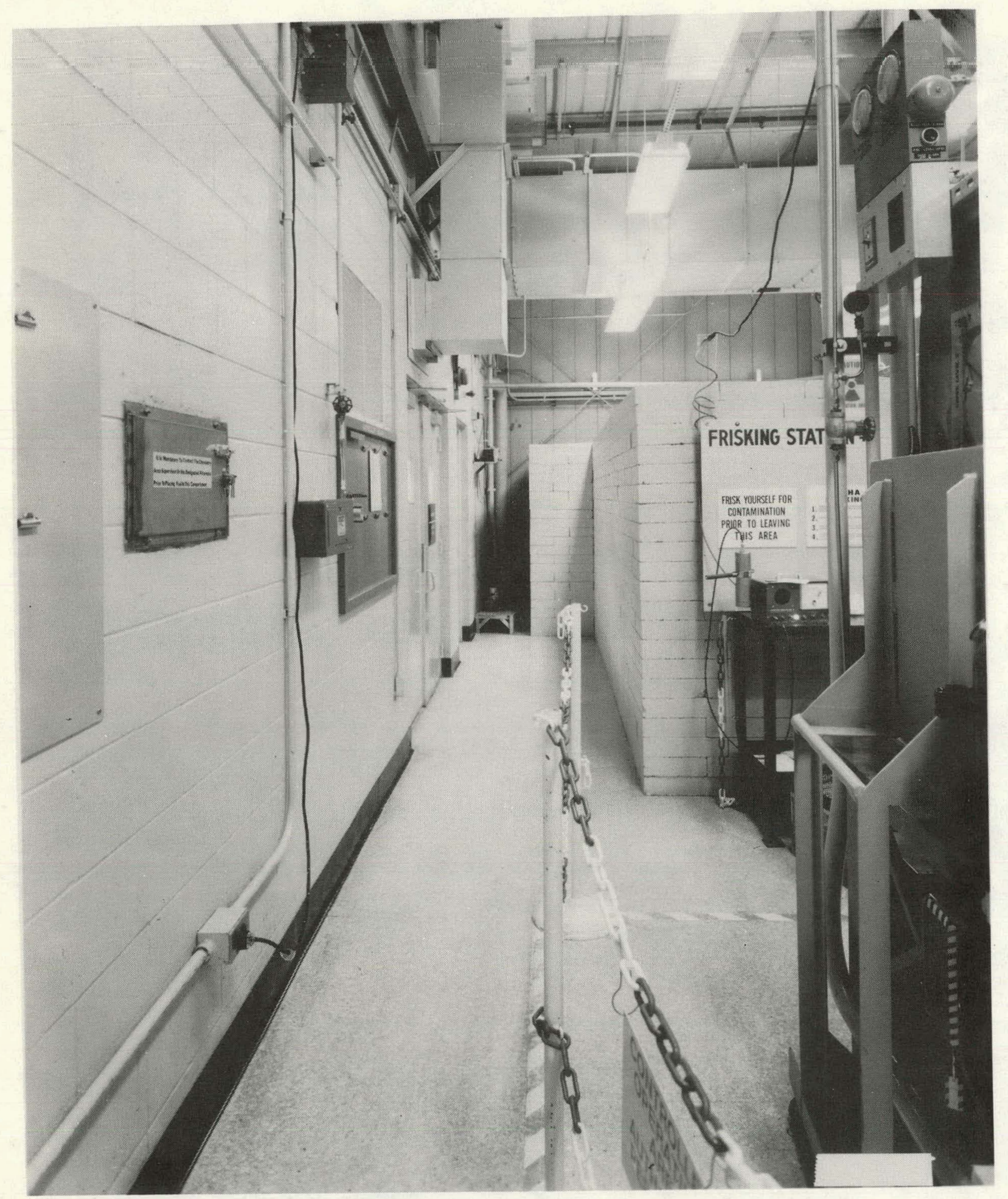

Figure 8. Binary Development Area Controlled Work Zone 
monitors located throughout the controlled areas. These instruments and samplers are described in Appendix A, and their locations are shown on Figure 5 . The continuous air monitors activated local visual and audible alarms when airborne alpha activity in an area exceeded the set limit. A local visual or audible alarm required immediate evacuation from the area or the donning of full face respirators

The exhaust gases were continuously monitored for gross alpha activity at the stack using an air monitor. The monitor activated visual and audible alarms both locally and at the Central Alarm Panel if exhaust activity exceeded 50 percent of the Bettis release limit. The unit was connected to the building emergency power system and would continue to operate during power failures. $\AA$ standby monitor was available for use if the on-line monitor failed and/or required repairs. The monitor was further supplemented by a continuously operated filtered air sampler.

f. Area Monitoring and Surveillance-In addition to the above control, routine surveys of areas, materials, and equipment were conducted by Radiological Control as described in Appen$\operatorname{dix} A$. Due to the large a mount of routine work performed in the Binary Development Area that required monitoring for alpha contamination, it was found beneficial to train several manufacturing technicians to monitor some of these operations for contamination. These technicians, called alpha monitors, were qualified to monitor only certain specific routine operations. They were instructed to stop any operation and notify Radiological Control if alpha contamination was detected.

Numerous radiological survey instruments were available in the Binary Development Area for use as necessary by qualified operators and Radiological Control surveillance personnel.

g. Maintenance and Repair Control-Maintenance and repair work on contaminated systems in the radiolngirally rlean areas utilizcd gome type ul containment. The containment often consisted only of existing enclosures, but tents or polyvinylchloride (PVC) plastic enclosure bags with installed sleeves and gloves were required when the glovebox enclosures were breached. Emphasis was placed on the use of specially designed PVC plastic enclosure bags with installed sleeves and gloves rather than tents, where possible, to preclude sending personnel into highly contaminated areas and to reduce the size of the areas that became contaminated.

h. Internal Exposure Monitoring-All personnel assigned routine duties in areas handling unclad ${ }^{233} \mathrm{U}$ or thoria were included in the internal exposure monitoring program described in Appendix $A$. There were no instances of internal exposure detected during LWBR core manufacturing.

i. Liquid Effluent Control-Control of liquid effluents was maintained by requiring that all process liquids which came in contact with unclad fuel be placed in nuclearly safe containers and assayed for fissile fuel content. The liquids were then evaporated and/or solidified, packaged, and shipped to an authorized disposal or storage facility. Liquids potentially contaminated above acceptable limits were treated in filtration/ion exchange processing systems to remove most of the radioactivity and analyzed prior to release to ensure that the amount of radioactivity released was as low as practicable.

To ensure that no water that might come into contact with the controlled area floor was inadvertently released, no floor drains were connected into the sewer system. The floor was curbed around the perimeter of the building and within the building to control the flow of any water. Scuppers were installed in the floor which would drain overflow water to a catch basin where the water would be sampled and analyzed for alpha activity prior to release. There were no instances of accidental radioactive liquid release during $L W B R$ core manufacturing.

j. Solid Waste Disposal-Solid waste generated in the manufacturing area outside the gloveboxes was surveyed for alpha activity and disposed of accordingly. Solid waste generated in the glovebox system, however, was assumed to be contaminated with binary fuel; therefore it was placed in nuclearly safe containers which were collected and assayed for fissile fuel content. The containers were then disposed of as radioactive waste or placed in nuclearly safe storage devices. To minimize the possibility of the spread of contamination, a special waste packaging glovebox for packaging primary waste containers into secondary containment was provided. All waste drums were surveyed by Radiological Control before they were transferred to a waste storage area to await disposal.

\section{External Exposure Control}

With a few exceptions, gloveboxes in the Binary Development Area fuel manufacturing lines were shielded with lead glass windows and had up to 3 inches of lead shot or up to 1 inch of lead plate in their walls. Shielded gloveport covers that were hinged to swing in front of the gloveports when the gloveports were not in use were provided on the 
gloveboxes in which the large quantities of binary powder (25 to 100 kilograms) were processed prior to pellet pressing. The amounts of shielding designed into each glovebox were calculated to meet the design dose rates for each work station. A cross-sectional sketch of a typical shielded glovebox is shown in Figure 9.

The highest radiation exposures experienced in the Binary Development Area were associated with pellet grinding where the gloveboxes were not shielded initially. The nature of the operation whirh produced wet grinding sludge and the configuration of the equipment resulted in a continuing accumulation of material that could not be completely cleaned out of the gloveboxes and that increased in radiation intensity with age due to the growth of decay products. The gradual buildup in radiation intensity in the three pellel grinding gloveboxes during a particular fuel campaign is illustrated in Figure 1.0. In this ligure the average radiation level of six to nine marked survey puinls at work stations on the gloveboxes are plotted as a function of time between cleanups at the bcginning and end of the fuel campaign. This radiation level buildup proceeded throughout the six fuel campaigns and was only controlled by the addition of more shielding on the pellet grinding gloveboxes.

The largest single activity source in pellet grinding gloveboxes was from deposition of grinding sludge in a coolant recirculating line. Permanent shielding was added to these lines and glovebox faces. Removable shielding in the form of lead blankets and moveable lead sheets was added onto grinding boxes, the sludge drying furnace, and the sludge centrifuge boxes. With this added shielding, a reduction in the exposure rate for grinding personnel was realized even though the ainount of material in process and the age of deposited materials increased during the progress of manufacturing uperations.

Other high-radiation exposure operations were performed by the vault custodians and scrap packaging personnel. A series of shielded transport devices was provided to shield the person transporting fuel material. Additional shielding was installed on fuel storage vaults to reduce general area radiation levels. Movable shields (on casters) were utilized during physical inventuries to minimize exposures during weighing operations.

Steel hinged covers were added to gloveports on some boxes that were not initially provided with shielded covers but where significant amounts of material were processed. These covers were swung over the ports when the ports were not in use. Lead sheet ( $1 / 2$ inch thick) was also bolted onto the sides of these gloveboxes to provide extra shielding.
Transfer tunnels were designed only for passthrough of materials; hence, they had relatively litthe shielding. Occasionally during operation, temporary storage of material in a tunnel was necessary due to higher production at an earlier processing stage than could be accommodated by a later stage, usually caused by a maintenance problem at the later stage. When this occurred, the lemporary storage area was appropriately shielded with temporary shielding (lead blankets), or personnel access to the area was limited.

The accumulation of materials in the process line gloveboxes was munitored ruutinely fur radia. tion control purposes as well as nuclear safety and fuel inventory control purposes. The boxes were cleaned after completion of each fuel blend campaign, approximately 2 -month intervals, which reduced the goneral radiation levels near the boxes by a factor of as much as 50 percent. Areas that required special action were accumulations in exhaust profiltore and in tunnel jnints hetween boxes. Exhaust prefilters were changed regularly on a schedule diclated by nuclear sufcty rcquirements for limiting accumulations of fuel. This schedule was satisfactory from a radiation standpoint because the prefilters and their associated contamination were completely contained within the gloveboxes. Fuel powder accurnulations in the tunnel connectors between boxes were monitored routinely by Radiological Control and reported to operational management for cleaning when levels exceeded $22 \mathrm{mrem} / \mathrm{hr}$ beta-gamma. Since cleaning the tunnel connectors required a significant amount of time to open them while maintaining total containment, the areas were posted with radiation warning signs to alert workers to the higher radiation levels until the tunnel connectors could be cleaned. It should be notod that the hot spots (with contact readings as high as $200 \mathrm{mrem} / \mathrm{hr}$ beta-gamma) were localized and located such that they contributed little to the general radiation fields at the work stations.

Typical monthly average personnel exposures for different Binary Development Area manufacturing operations are listed in $\Lambda$ ppendix $C$.

\section{Fuel Rod Facility}

\section{Introduction}

The Fuel Rod Facility included two separate areas, the BC Aisle and the Core Module Assembly Area (CMAA). Fuel rods were corrosion tested and inspected in the $B C$ Aisle and were assembled into core modules and prepared for shipment to the Shippingport plant in the CMAA. These facilities were operated as clean areas, as unclad fuel was not permitted in them. Fuel rods 


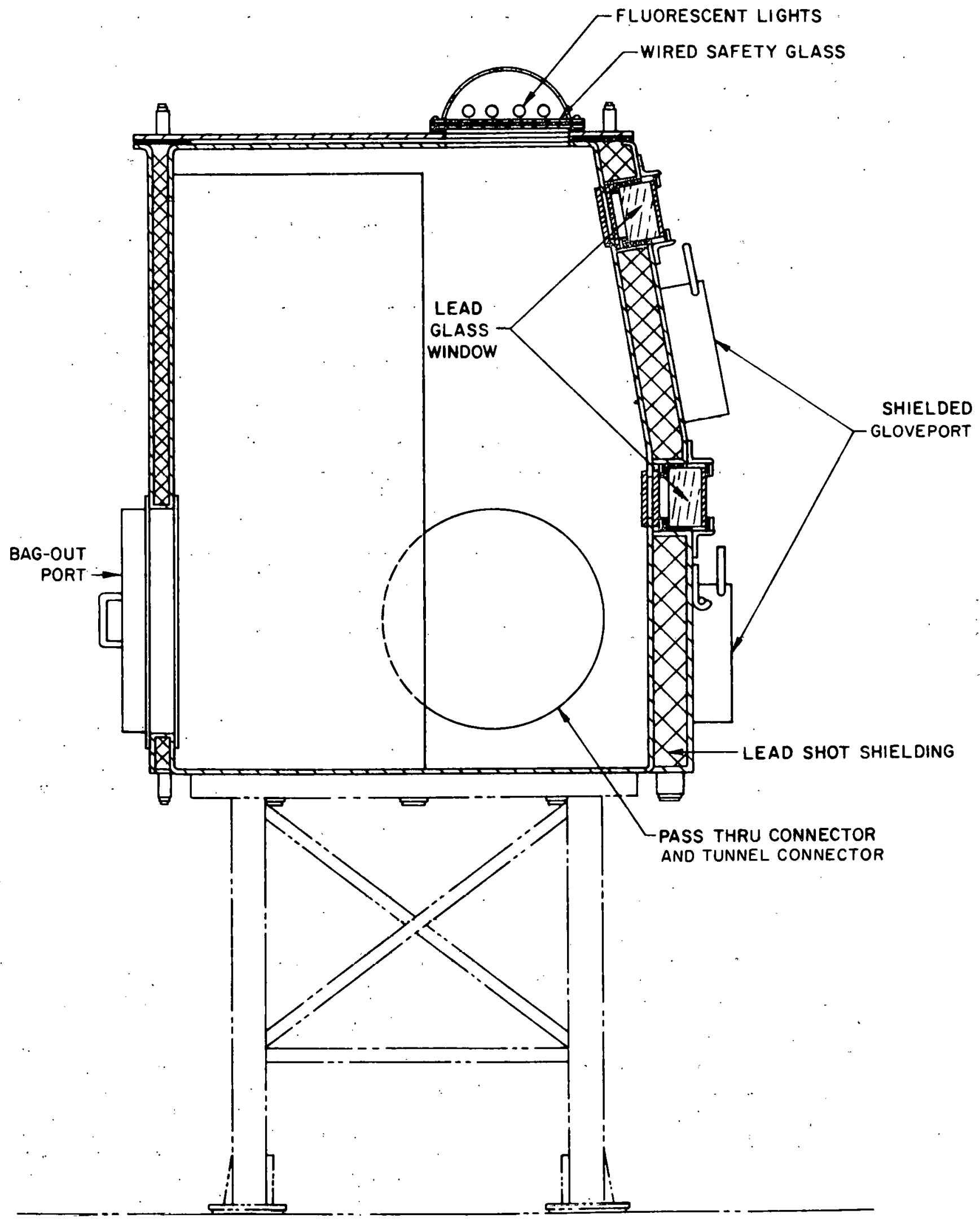

Figure 9. Cross Section of a Shielded Glovebox 


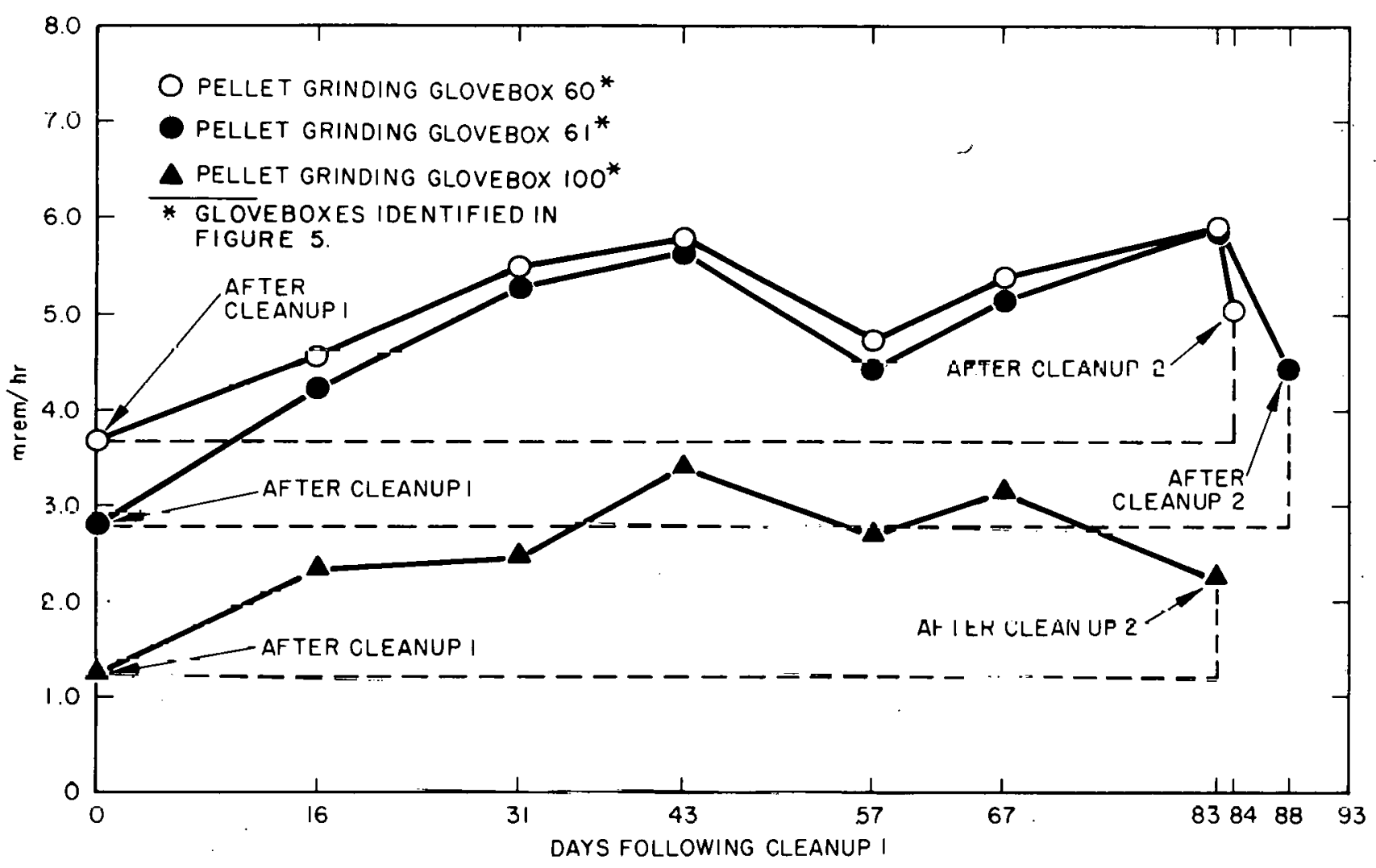

Figure 10. Radiation Intensity Buildup in Pellet Grinding Gloveboxes

were surveyed and met clean limits prior to transfer into the facility. Contamination incidents in these areas were considered unlikely.

The air handling systems in the Fuel Rod Facility were designed primarily to provide for personnel comfort. Since no unclad fuel operations were conducted in the building, no filter systems were installed in the area exhausts. The air handling system in the CMAA portion of the building normally maintained that area at a slightly positive pressure to maintain clean room conditions with the exhaust passing through high efficiency filters and recirculated air passing through intermediate efficiency fiberglass filters. To minimize fission product release to the environment in the unlikely event of a criticality incident, the electrical power to all exhaust and outside supply an systems in both the BC Aisle and CMAA were interlocked with the Fuel Rod Facility Criticality Alarm System such that all exhaust and outside supply air systems would automatically shut down if any detector in the system became actlvated.

The above areas were routinely monitored by Radiological Control. In the unlikely event of an activity release or spread of contamination, the enieigeney plan roquired that tempnrary controls be established until the problem was corrected, and portable survey instruments, friskers, and airborne activity monltors west available for use in these facilities if the need aroge. No aotivity release or sprcal of contamination was experienced.

\section{BC Aisle}

The BC Aisle was uperated as a controlled Radiation Area, as only loaded fuel rods were received into this area from the Binary Development Area. Since the fuel was encapsulated in rods, the only radiation exposure concern was in handling the unshielded fuel rods for machining, treatment, tesliny, and inspection. Treatmunls in: linded vapor blasting and pickling. Tests included helium leak tests and autoclave testing. Inspections included alpha monituring, radiography, and visual and dimensional checks. In addition, tubing was clcancd, the initial end rap was welded onto the tubes, the weld was machined, and the tubing was inspected prior to pellet loading in the Binary Development Area. The arrangement of the facility 
w- ade such that personnel working on nonloaded tubing were not exposed to the radiation from loaded rods.

The average exposure of personnel working in the BC Aisle was maintained at a lower value than for those persons in the Binary Development Area; for example, $50 \mathrm{mrem} / \mathrm{mo}$ was the average in the $\mathrm{BC}$ Aisle versus $100 \mathrm{mrem} / \mathrm{mo}$ in the Binary Development Area. This was accomplished by the extensive use of shielded work tables where the manufacturing technician or inspector was exposed only to the radiation field from the single rod that he was working on, and this field was shielded, if possible, while remaining rods in the area were stored inside lead coffins. Since the radiation field from the rods was much greater in the middle of the rod than at the ends, two-man rod handling fixtures, with a man on each end, were used whenever possible. Figure 11 shows the shielded work tables associated with the storage and in-motion radiography inspection of fuel rods (storage coffin on shielded work table on right side of photograph).

To minimize the exposure of manufacturing personnel handling boxes of fuel rods, a number of actions were taken. The fuel rod boxes that re. quired two men to lift them were designed so that they could be lifted only at the ends of the boxes, thus reducing the radiation field by a significant factor. (See Section I.B.3 for typical radiation levels on a fuel rod box.) Also, the transport carts were designed so that the person pushing the cart was exposed only to the radiation field at the end of the fuel rod boxes. The equipment used to move boxes into and out of the storage vaults was designed to operate the movement mechanism at the end of the box and at as great a distance from the vault as possible. At the corrosion testing autoclaves, where some delay in using the rods could be encountered, a zone for temporarily storing the fuel cart was designated. A $0.5 \mathrm{mrem} / \mathrm{hr}$ barrier was erected and personnel could not approach the area except to place or remove the cart.

Significant exposures were experienced in consolidating tuel rods in boxes. Individual rods were removed from boxes for various production reasons, and consolidation of the rods in boxes was necessary because of limited vault space and variable hold times required for processing inspection records prior to releasing the rods for insertion into modules. Two additional fuel rod storage vaults were added which minimized the need for consolidation, thus reducing personnel exposures. Fuel rod storage vaults and shielded work tables are shown in Figure 12 along with a fuel rod box transport cart in the foreground.
Typical average monthly exposures for the different BC Aisle manufacturing operations are listed in Appendix C.

\section{Core Module Assembly Area (CMĀA)}

In the Core Module Assembly Arrea the fuel rods were drawn into the grids to form the core modules and the final structural components were attached. Numerous detailed inspections were made on the assemblies, trial fits of the modules were made, and then the modules were prepared for shipment. Operations in the CMAA were unique to the manufacturing and inspection process of core fabrication in that it was the only area where dose rates were such that a person could obtain a significant exposure in a short period of time. Peak surface dose rates measured at about $l$ inch on seed or blanket modules ranged from 600 to $2000 \mathrm{mrem} / \mathrm{hr}$. As a result, large amounts of specially designed operational shielding and stringent and well-planned engineering procedural controls were utilized to control personnel radiation exposures.

The CMAA occupied an area approximately 114 feet by 50 feet. A floor plan is shown in Figure 13. The west area of the CMAA was a radiation area and was used primarily for the preliminary assembly and checkout of seed and blanket fuel modules including thoria fuel rods. Structural steel stands and decking, designated in Figure 13 by $\mathrm{Pl}$ through P6, were provided for these operations. $\bar{A}$ blanket module storage area was also located in this area along with a ground floor personnel change room with a mechanical equipment room above it to house the CMAA ventilation system equipment. The change room and equipment room were constructed with concrete block walls and reinforced concrete floors and ceilings. Figure 14 shows the construction of the blanket module storage area.

The central portion of the CMĀA was a high radiation area where fuel rods containing binary fuel pellets were installed in either seed or blanket modules. (Äreas identified as B1, B2 and B3 in Figure 13 were rod pull stations.) Concrete shielding walls (24 inches thick) enclosed and partitioned off this area to minimize radiation exposure to personnel in the CMAA. Within this central portion of the CMAA were two storage areas, one area for storage of reflector modules and another for storage of seed modules and one blanket module. A sketch and photograph of this central portion of the CMAA are shown in Figures 15 and 16. A shielded elevator was available at each of the three fuel rod pull stations for observing the rod being 


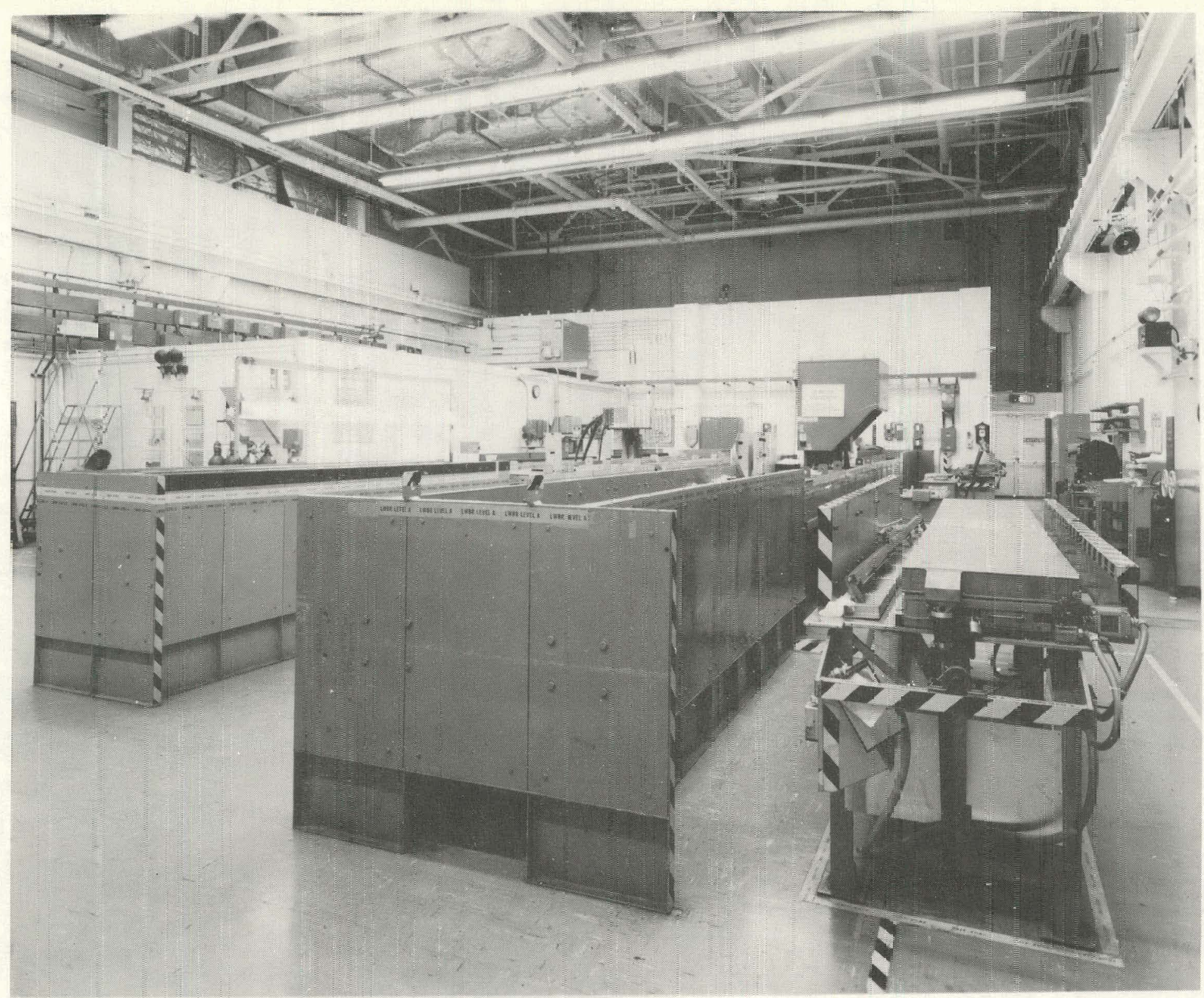

Figure 1l. Shieldec Work Tables 


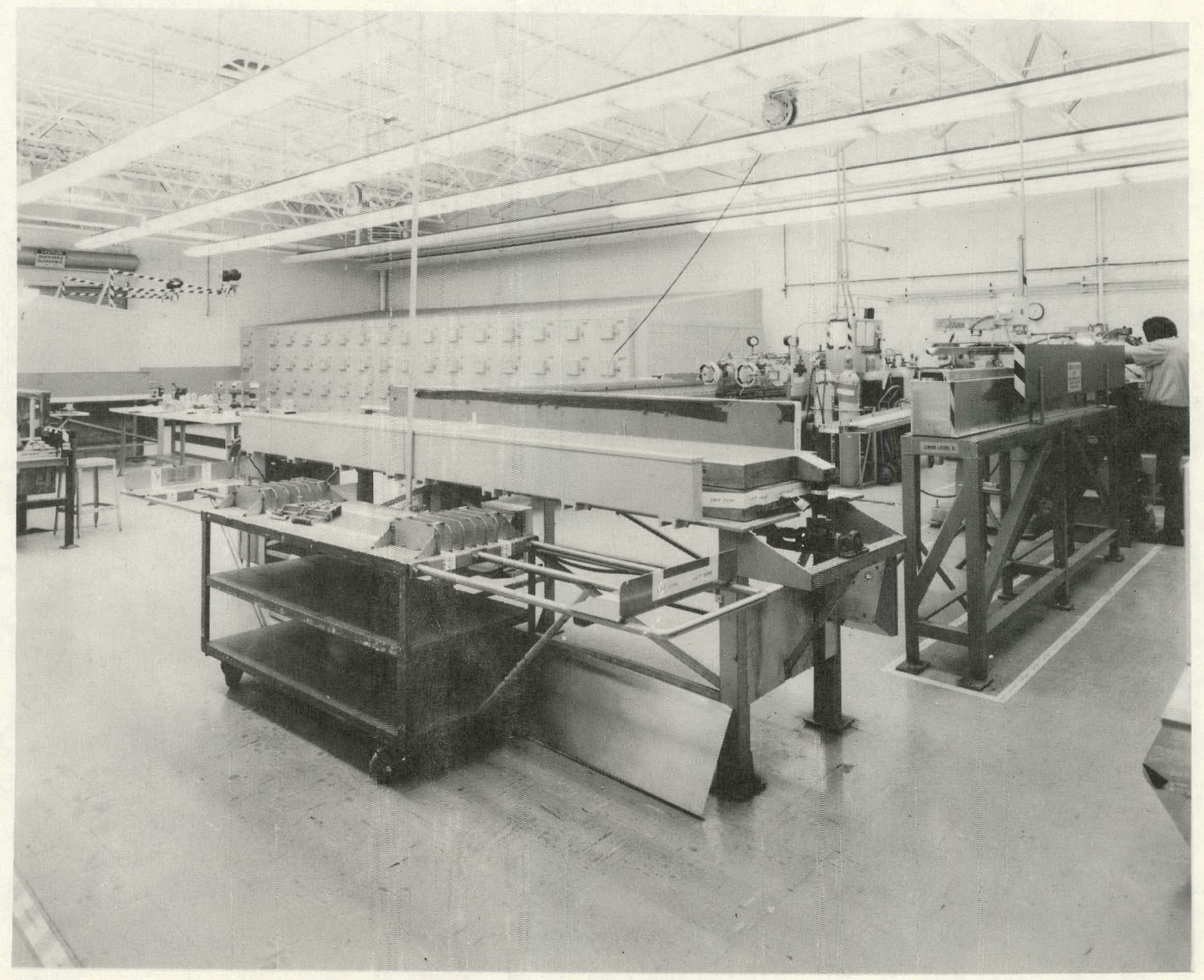




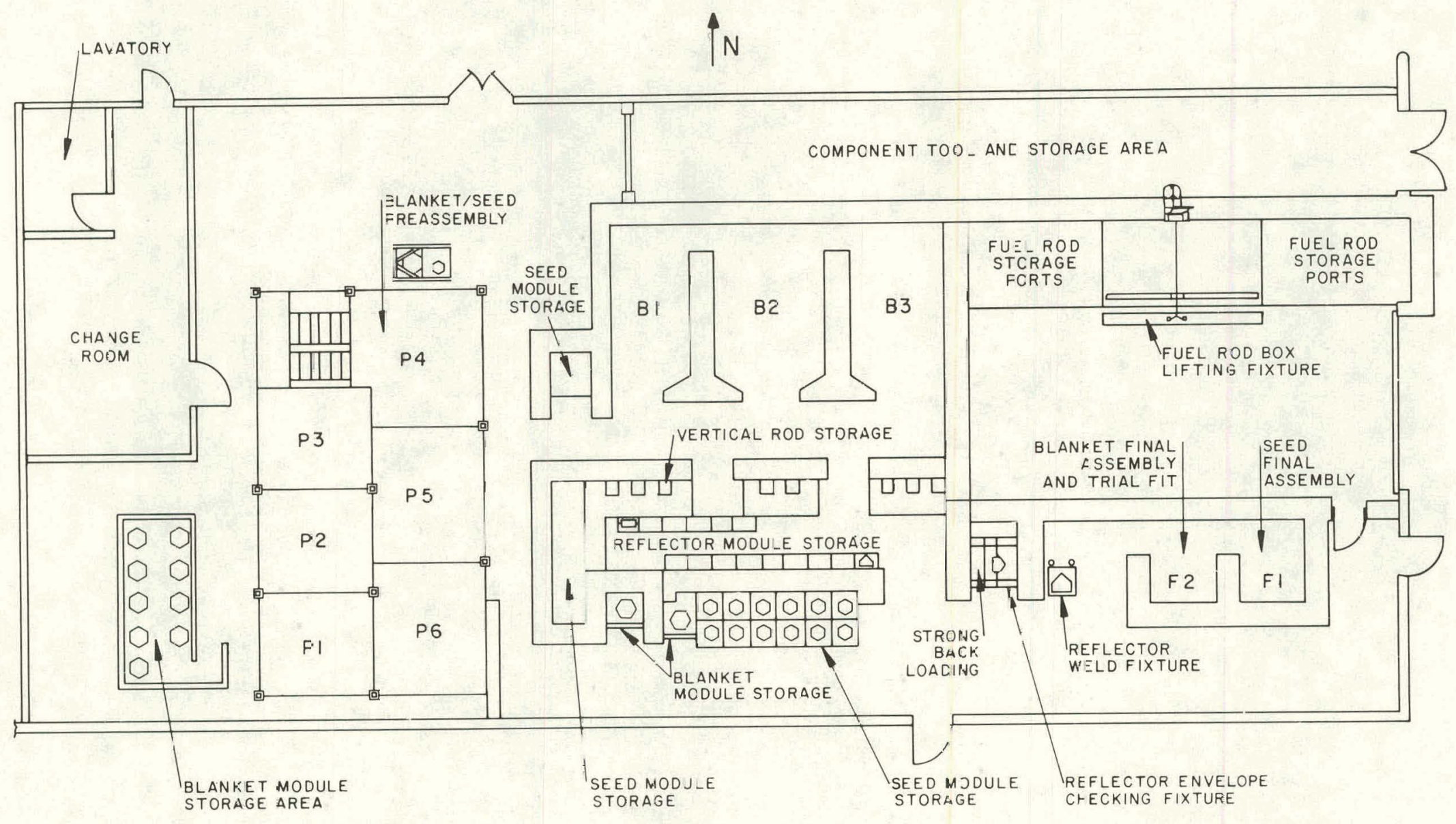

Figure 13. Core Module Assembly Area 


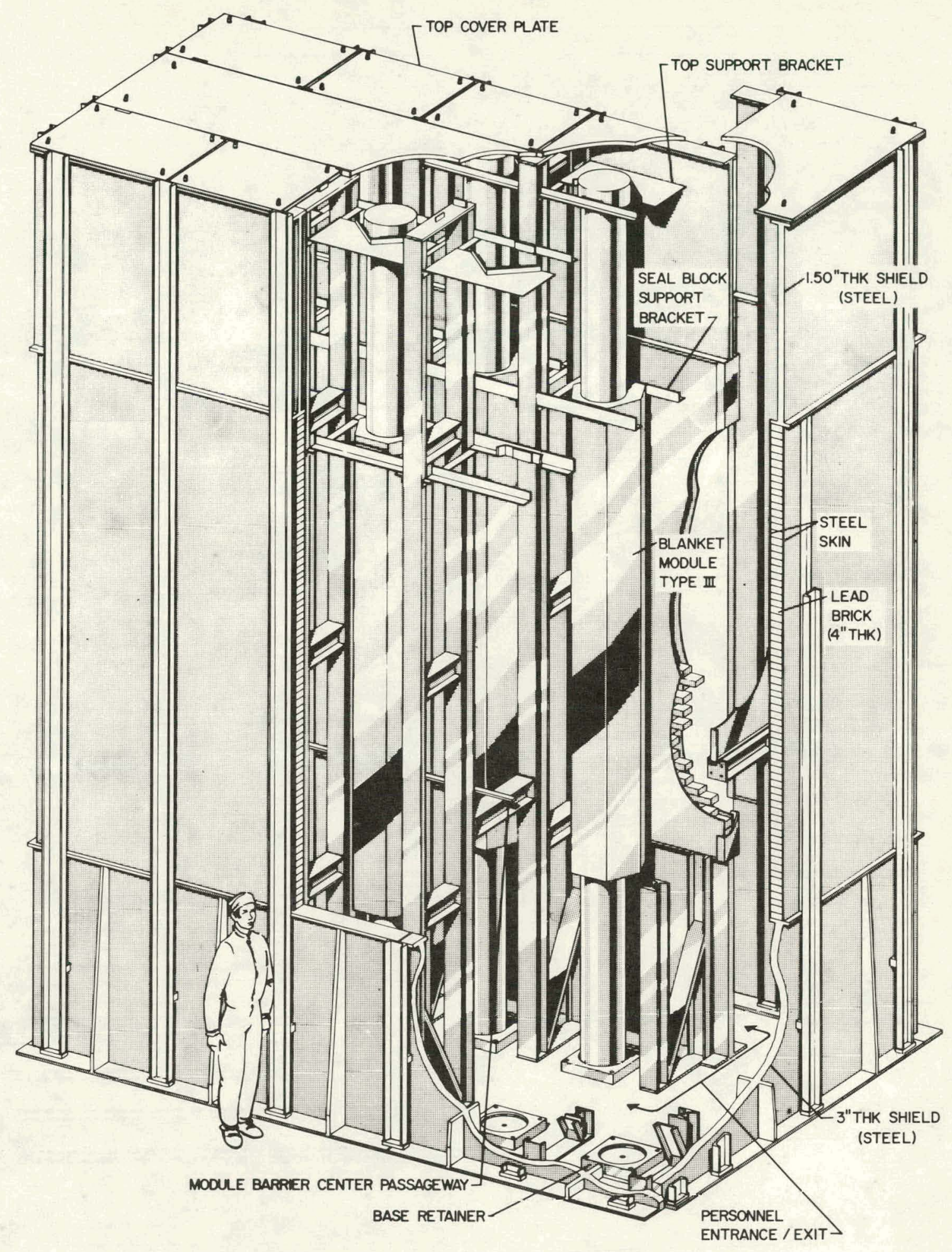

Figure 14. LWBR Blanket Module Storage Area 


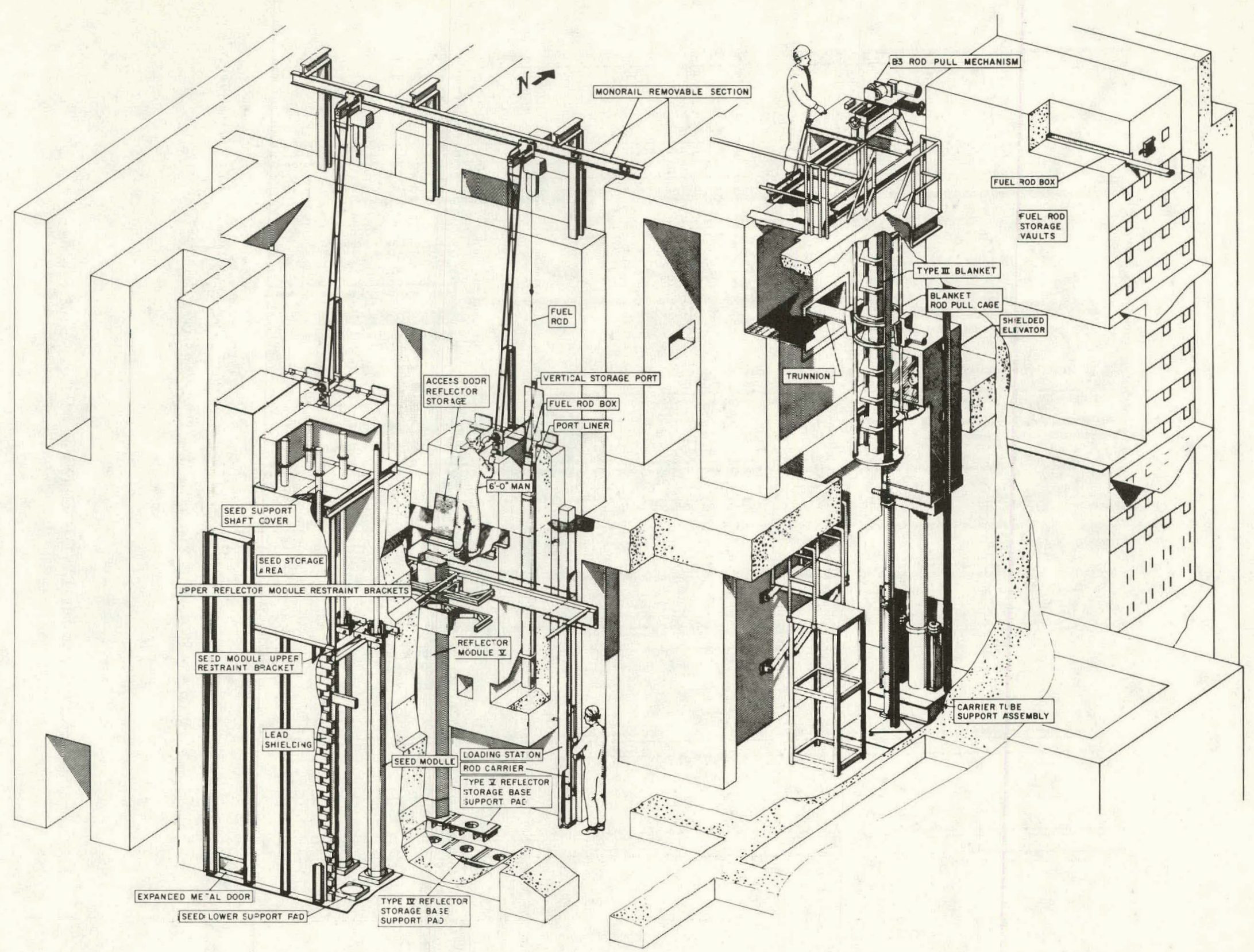

Figure 15. CMAA Binary Fuel Rod Handling/Pulling Operations 


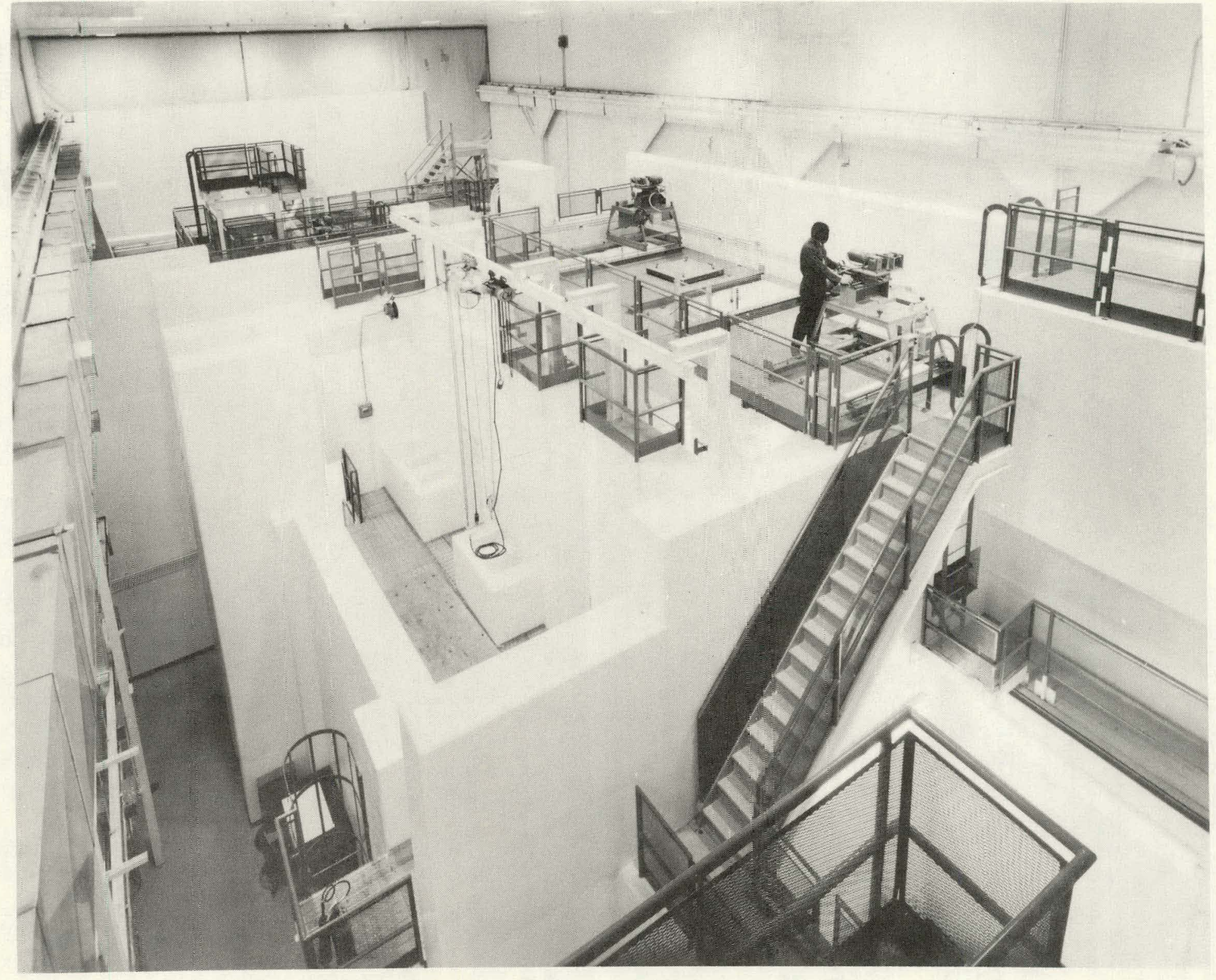

Figure 16. Top View of CMAA Binary Fuel Rod Handling Operations Seed Storage Area not shown) 
pulled up into the module assembly and for making specified rod to rod spacing measurements. One of these shielded elevators is shown in Figure 15

The east area of the CMÄ was a high radiation area for final module assembly, trial operations, and subsequent preparation for shipment. Concrete walls ( 24 inches thick) provided shielded work stations for the assembly of the balance of the seed or blanket assembly structural components and also for the trial fit operation of a mated seed and blanket assembly. Within this area, provisions were made to perform envelope checks and shell bolt welding operations on reflector modules. These operations were carried out in the areas identified as F1 and F2 in Figure 13. Following final testing, the seed and blanket assemblies were prepared for shipment to the Shippingport site in separate shipping containers. Fuel rod stordye was also provided in this area in the form of 144 horizontal, boron-poisoned ports imbedded in blucks of pourcd concrete

CMĀA work stations were shielded based upun the assembly and inspection procedures initially anticipated. However, as the manufacturing program proceeded, additional inspections and operations were added. Each new step was analyzed to develop the most efficient procedure possible while minimizing exposure. The methods used included engineering modifications to minimize the time required for the operation, adding shielding as practicable, and modifying the techniques used to obtain the desired inspection result while minimizing the individual exposures. To accomplish this, each operation planned required review by manufacturing engineering and inspection and radiological personnel tar in advance to have sullicient time for modification of the facilities and equipment. Âlso, detailed review of procedures and training operations with dummy modules were carried out prior to actual operations. Surveillance by Radiological Control was required during many operatinns involving unshielded modules. Examples of some of these exposure reducing actions are given below.

The modules had a much higher field near their center lines than at their ends because 1) the ends of the rods were loaded with thoria pellets rather than binary pellets and 2) the thoria exhibited selfshielding effects. 'l'herelore, when possible, wurk was accomplished with the worker positioned at the ends rather than at the middle of the module. Additionally, the number of personnel in close proximity to the module was limited to the number of people necessary to accomplish the particular job. As an example, when modules were moved, the hook-up to the crane was made at the module top. In transit, only the crane operator and his guide were allowed in the general vicinity. On setdown, one worker and one supervisor worked from below the module to guide the module into its fixture and attach it.

As an example of an engineering modification to minimize exposure, nylon guides were designed to align and guide the shell while it was being placed over the seed rod assembly. Using this modification, personnel did not have to guide the shell by hand, which would have exposed them to a higher dose rate from the assembled rods.

Modifications to shielding and tooling for accomplishing additional inspections were numerous. For example, a 100-percent inspection of lock welds and a requirement for filing of lock weld beads on shell bolts were added. Âs a temporary solution, a shield of lead blankets with a lead glass window was utilized until tooling could be developed to do the job from hehind permanent shielding.

In some cases the inspecliun requircmonts were modified to obtain the desired results while minimiziny the cxposure. As an example of this, rod to grid spacing measurements were required which could not be accomplished from a shielded position. Originally exact dimensional measurements at each location were to be made. The procedure was modified to use go/no-go measurements followed by more exact measurements, if indicated. This modification gave the measurement reliability needed and reduced the exposure by a factor of 10 .

Typical monthly average personnel radiation exposure for the CMAA operations are listed in $A$ ppendix C

\section{LWBR OPERATIONAL SUP- PORT GROUP}

\section{A. Introduction}

As identified in Section IV, a special group was established within the T.WBR core manufacturing organization to werk unly un LWBR coro manufarturing problems associated with imprnving radioactive contamination control and reducing personnel radiation exposures. This group had responsibility for investigating and identifying basic causes of conldmination and radiation expnsure problems and providing appropriate corrective actions, carrying out development programs, and coordinating all actions relating to improving control of radioactivity and radiation exposures in the LWBR core program. The following are items of significance that this group contributed to the overall radiological control program by the application of direct attention to specific problem areas. 


\section{B. Glovebox Gloves and Protective Gloves}

During initial LWBR core fuel manufacturing operations, glovebox glove failures were occurring at a high rate with as many as 4 percent of the gloves per week indicating leakage. With over 1200 gloves in the Binary Development Area gloveboxes, productivity losses were considered excessive due to the time involved in the replacement of gloves and the decontamination of equipment and personnel clothing. As a result, all commercially available glovebox gloves were investigated, and the ones that showed the best operating characteristics under LWBR core fuel manufacturing conditions and met process material requirements were selected for use. However, the commercially available glovebox gloves did not have an adequate service life nor did they provide adequate protection to glovebox operators. Consequently, an attempt was made to have a reinforced glovebox glove developed which would provide improved wear, puncture, tear, and abrasion resistance resulting in improved service life. This eftort was subcontracied, but the results proved negative and additional development was considered uneconomical within the time period available. However, as a result of this work, a fabric reinforcement was applied to the cuff of a commercially available glovebox glove which improved the service life of the glove. These reinforced gloves proved to be most effective in the press, micronizer, grinder, and grinder sludge glovebox gloveports where wear at the gloveport and considerable stretching occurred.

Under the LWBR core manufacturing conditions and the process material requirements, it was found that the best glove performance was obtained when

1. Milled neoprene ( $30 \mathrm{mil}$ ) rubber gloves were used on all gloveboxes in the manufacturing line up to and including final inspection.

2. Natural latex (25-35 mil) rubber gloves were used in the degas furnace and rod loading area gloveboxes.

3. Butyl (30 mil) rubber gloves (washed with alcohol and conditioned under a vacuum to remove volatile sulfur compounds) were used in the rod welding box.

4. Hypalon $(30 \mathrm{mil})$ rubber gloves were used in the chemistry and metallographic laboratory boxes where high concentrations of acid came in contact with the gloves.

Buna-N rubber glovebox gloves were found to have a very short service life due to aging, and their use was not permitted. The milled neoprene and butyl rubber gloves did not show problems with aging, while the natural latex rubber gloves deteriorated (aged), in 2 to 3 months.
Quality control checks were made on milled neoprene glovebox gloves twice a year to ensure that they met manufacturer's specifications. These checks included tests for modulus, elongation, tear, puncture, abrasion, high voltage, thickness, and permanent set.

To aid in prolonging the service life of the glovebox gloves, monthly inspections were made to eliminate glovebox glove cutting, snagging, and tearing hazards from the glovebox. Where possible, equipment was designed to eliminate or reduce the need to stretch the gloves to perform necessary operations.

The puncture, abrasion, tear, and snag resistance of the available glovebox gloves was found to be less than desired. As a result, a requirement was established to provide additional protection to glovebox operators with secondary protective gloves (gauntlet). Approximately 30 different types of gauntlet gloves were evaluated, and latexnitrile gloves were found to provide the best tear, puncture, and abrasion resistance of those tested. As a result, this type of glove was used for secondary protection of the glovebox operators.

In addition to rubber $O$-rings, a metal band clamp (with a worm-drive tightener) was used to hold the glovebox glove securely onto the gloveport. An inner band clamp was designed, built, and provided for use within the gloveport to reduce the migration of fuel particles to the O-ring and outer band clamp holding the glove on the port.

To aid in changing glovebox gloves, Dow Chemical Corporation Rocky Flats-type glovebox glove change rings were provided. On the gloveboxes where these could be used, a time saving of about 75 percent for each glove change could be realized. This resulted from prestretching the new glove on the change ring prior to placing it over the old glove and, in most cases, eliminating the need for decontamination of the gloveport flange.

\section{Containment Development}

\section{1. Ārea Contamination Containment De- vices}

It was found expedient to utilize two different types of area contamination containment devices for performing repairs on radioactively contaminated manufacturing equipment employed in the production of the LWBR core. These were tent enclosures and polyvinyl chloride (PVC) plastic baq enclosures. Tents were used to enclose contaminated areas while repairs were performed inside them by personnel protected by anticontamination clothing and forced air breathing apparatus. Flexible PVC plastic bag enclosures were used to contain smaller contaminated items 
whenever possible. These enclosures were equipped with glove sleeves and other attachments so that personnel could perform repairs without entering the containment.

The program for upqrading area contamination containment devices resulted in the following improvements. Tents were initially erected by stapling the tent material ( 22 mil PVC reinforced with nylon fabric) to wood strips fastened to metal supporting framework and making the final seal with reinforced cloth adhesive tape. $A$ procedure for sewing tents and hanging the tents from the metal framework was implemented which contributed to a significant reduction in construction cost and maintenance time. Originally only twocompartment tents were used, however, it was found that three-compartment tents (Figure 17) were much more effective in confining repair jobs with very high particulate radioactivity levels and in reducing the potential for personnel skin contamination on exiting the tent. The use of an auxiliary exhaust ventilation system equipped with HEPA filters was also provided and effectively controlled airborne particulate radioactivity levels in the tents.

The PVC plastic bag enclosures were used wherever possible to contain contamination from an opened contaminated system within the smallest area and to reduce the potential for personnel contamination. In addition, a siqnificant saving in cost and time was realized through the use of baq enclosures rather than tents. This was associated with the high cost of erecting tents, the cost of the necessary anticontamination clothing for use in the tent, and the time lost on the job due to anticontamination requirements in dressing and undressing personnel and decontamination of the larger areas involved with tent use.

Commercially available PVC plastic bag enclosures in assorted sizes and configurations were utilized primarily for working on small items such as valves, piping, and furnace stoking rods. For larger repair operations, special PVC plastic bag enclosures were designed and custom made to tit the equipment and provide the facilities required for specific repair jobs. Features provided in some designs that were not found in the commerically available bags included

a. Rectanqular shape (for use with most access ports in the Binary Development Area)

b. Ability to collapse the bag into an access opening to reach an interior work area

c. Transfer sleeves of sufficient size to transfer panels, windows, and large components into and out of the bag

d. Ability to store large objects within the bag during repair work

e. Ability to use a lifting device to move heavy objects within the containment f. A half-man suit (Figure 18) to provide better vision and greater accessibility to the equipment being repaired.

There were approximately 14 types of special PVC plastic bag enclosures used routinely in LWBR fuel element manufacturing maintenance and repair operations. When tents were employed, it was found that operational efficiency was improved by at least a factor of two when air supplied vortex type cooling vests were utilized under the required anticontamination clothing.

\section{Glovebox Bag-In/Bag-Out Sleeving}

PVC sleeving was found to be much superior in most instances to polyethylene for the containment of materials undergoing bag-in/bag-out operations and for the storage of contaminated items becaus $\epsilon$ of its strength and tear resistance.

\section{Binary Development Area Protec- tive Clothing Requirements}

l All nperating shop persnnnel were renuired to wear green coveralls and Companysupplied yreen lipped safety shoes when working in the Binary Development manufacturing area.

2. Latex-nitrile gloves, taped to the green coverall sleeves, were required when performing work in glovebox gloves and on gloveboxes, including changing glovebox gloves and bags and performing bag-in or bag-out operations.

3. Latex-nitrile gloves were required whenever containers of ${ }^{233} \mathrm{UO}_{2}$ powder were handled.

4. Terrycloth protective sleeves taped to the green coverall sleeves were required when wurkinc in the arinding area qloveboxes. (This included gloveboxes utilized in processing grinder sludge.)

5. Anticontamination clothing was used only on special preplanned jobs that involved direct contast with contaminated equipment. Radiological Control approved all clothing requirements and opcrational procedures for performing the job prior to its initiation

\section{E. Rem Reduction Actions}

Supplementing the overall Rem Reduction Program actions described in Section IV. 2 , several actions were initiated for specific operating areas in which personnel were experiencing higher radiation exposures. Examples of such actions were:

1. Existing work practices, procedures, and work instructions were evaluated in detail to identily changes which would result in rem exposure reductions. The changes were then implemented. 


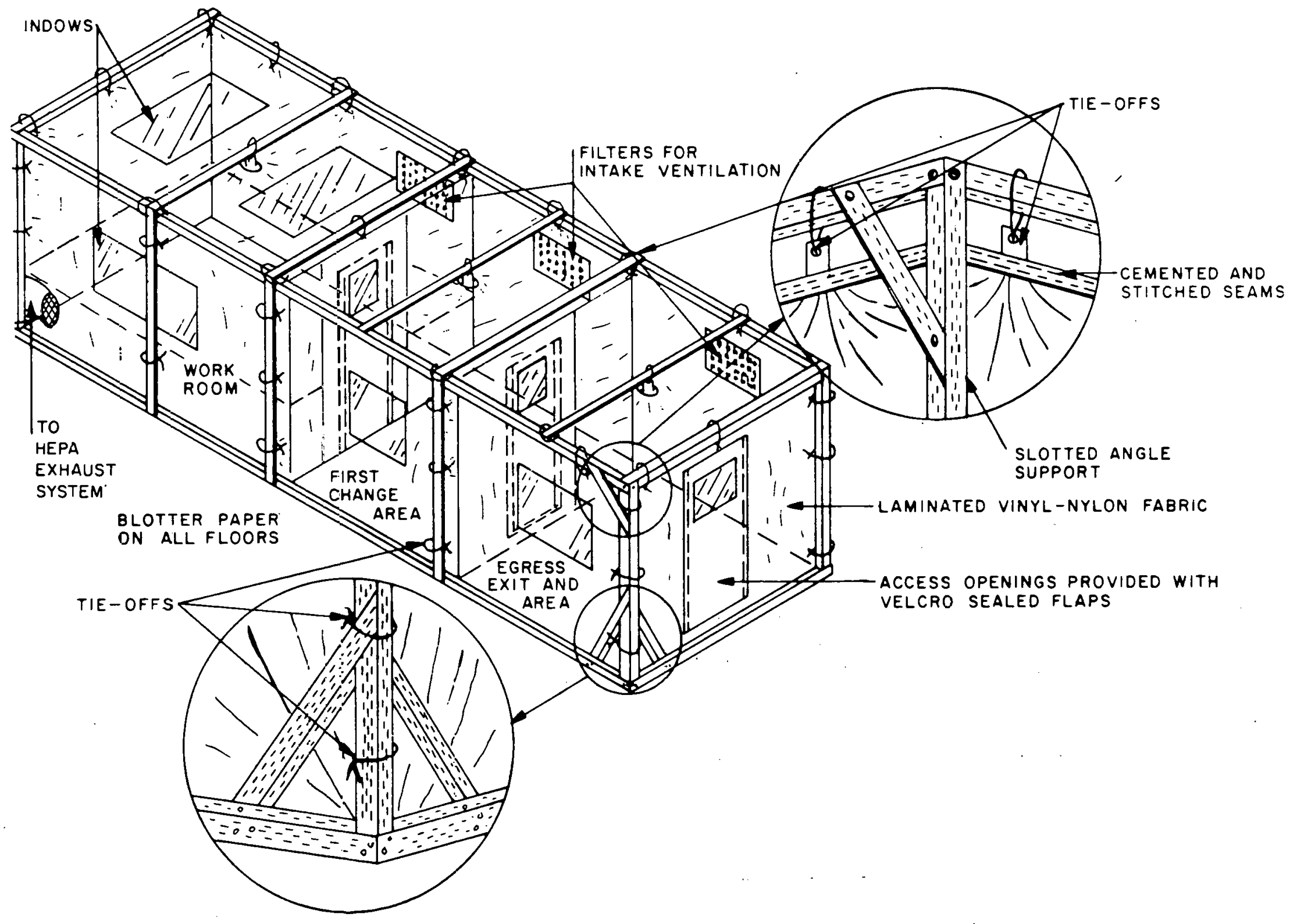

Figure 17. Properly Constructed Tent-Type Enclosure 


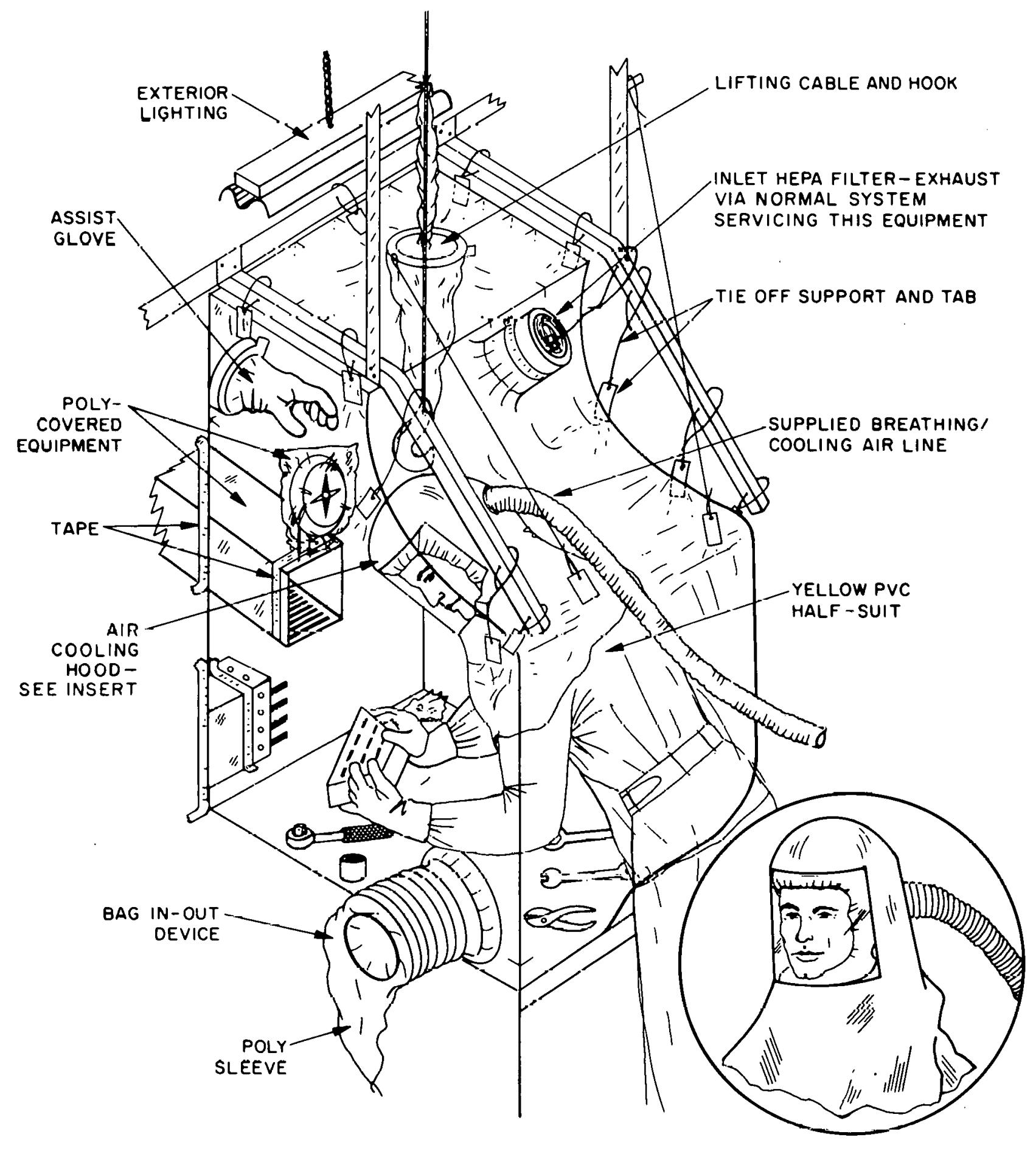

Figure 18. Special Half-Suit Containment for Repairing Internally Contaminated Equipment 
2. Detailed area radiation surveys were made, the data were evaluated, and permanent or temporary shielding was installed where indicated. Also, area maps which were color coded to point out varying radiation fields in the area were posted. Examples of these maps are shown in Figures 19 and 20.

3. Information to promote rem reduction was developed for presentation at weekly area workplace meetings.

4. Shielded carrying devices or carts were designed and procured for movement of fuel and scrap cans, eliminating hand-carrying wherever possible.

5. Special emphasis was placed on reducing fuel inventories in working areas, more frequent cleaning of containments and replacement of items creating radiation hot spots such as filters and sponge rubber mats in gloveboxes.

6. Equipment and fuel storage was rearranged where practical and beneficial for rem reduction.

7. The use of remote viewing and pellet conveyor equipment on the pellet grinders was evaluated.

8. Two-man fuel rod handling devices were designed and built to replace one-man fixtures for use at several work stations.

9. Personnel were instructed in the use of survey instruments so that they could personally measure the radiation fields in their work areas.

10. Radiation exposure rate chirping devices were used as precautionary warning devices for high radiation fields.

11. Preplanning and organizing job assignments, including dry runs, before entering high radiation areas were emphasized.

12. Closer supervision of operating personnel. with respect to their radiological work practices was implemented.

\section{F. Surveillance}

Intermittent surveillances of radiological work practices in the LWBR core manufacturing areas by management and nonassigned groups proved necessary to control compliance with criticality and radiological safety procedures and to minimize personnel radiation exposures. These surveillances covered three shift operations and were conducted by manufacturing and operational engineers along with Radiological Control, Criti- cality Control, the special LWBR group, and Department of Energy personnel

\section{SUMMARY OF OVERALL RE- SULTS AND LESSONS LEARNED}

\section{A. Radioactive Material Contain- ment}

The LWBR Core Manufacturing Program was carried out with no accidental radioactive material released to the environment and with only minor local area accidental particulate releases occurring. All releases were contained in localized areas within the facility in which they occurred with no personnel showing evidence of radioactivity deposition internally or externally following decontamination. These releases resulted primarily from glovebox glove failures. Other causes of releases included

1. Failure to comply with existing procedural requirements

2. Inadequate equipment/tools for the task being performed

3. Procedural deficiencies

4. Lack of formal procedure

5. Lack of proper training of personnel

6. Malfunctioning frisking equipment.

The glovebox integrity was primarily limited by the integrity of its glovebox gloves. Glovebox glove failures resulted from wear, aging, overstretching, pin holes, abrasions, tears, and punctures occurring during manufacturing operations. Since no commercially available glovebox gloves provided sufficient protection, secondary protection was provided to the personnel. The secondary protection included rubber (latex-nitrile) gauntlet gloves which were taped to the personnel's coveralls and were required for work in gloveboxes for protection from skin contaminations. Additional protection, such as latex-nitrile or leather gloves worn over glovebox gloves for certain repair operations and terrycloth sleeves for work in the grinding area, was provided. An attempt was made to fabricate a glovebox glove with the desired reliability, however no satisfactory prototype was produced. An improved glovebox glove was fabricated by cementing a fabric reinforcement in the cuff area of commercially available neoprene gloves. These gloves were provided for use in gloveboxes where 


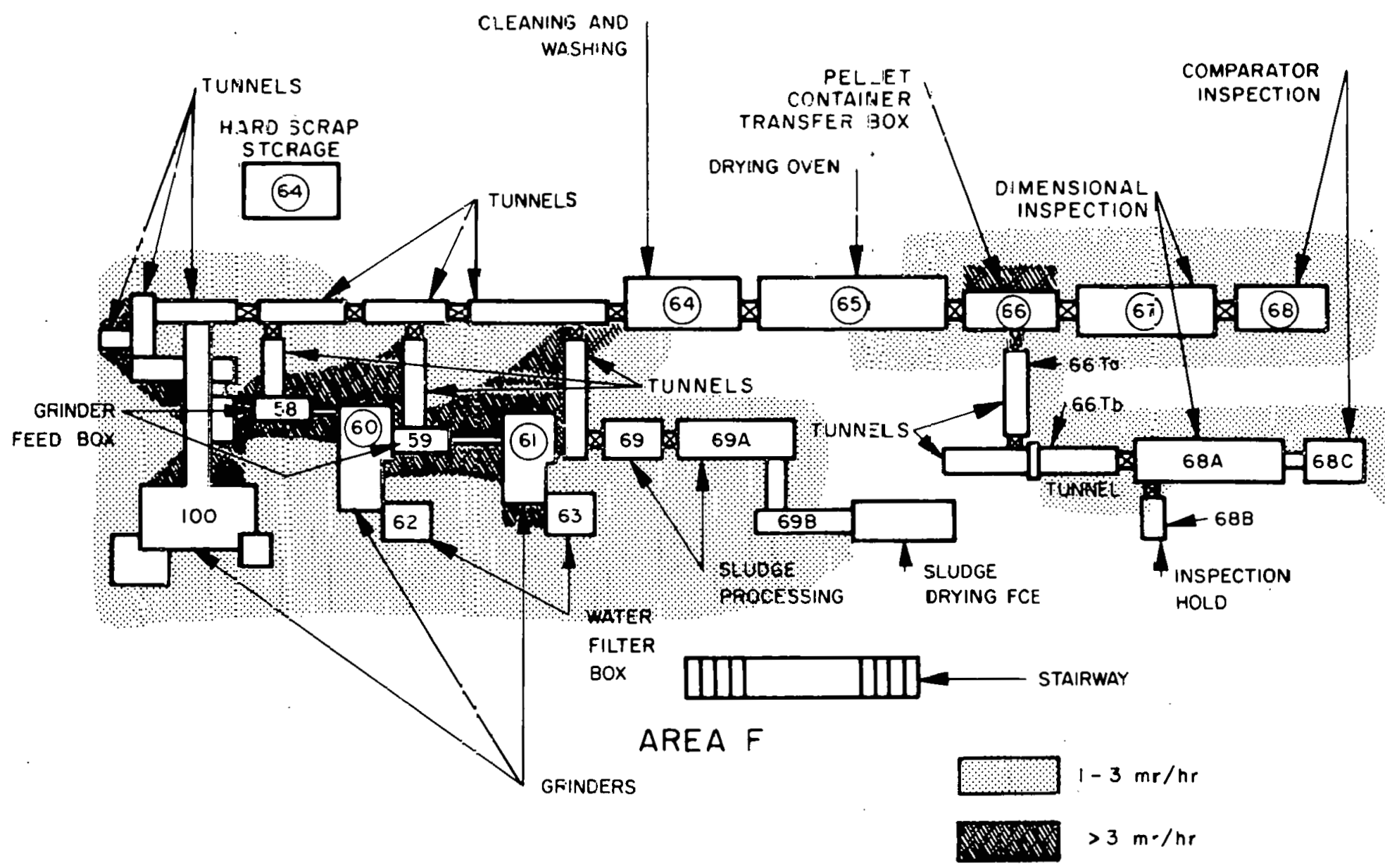

Figure 19. Sample Area Radiation Survey Map (Binary Development Area) 


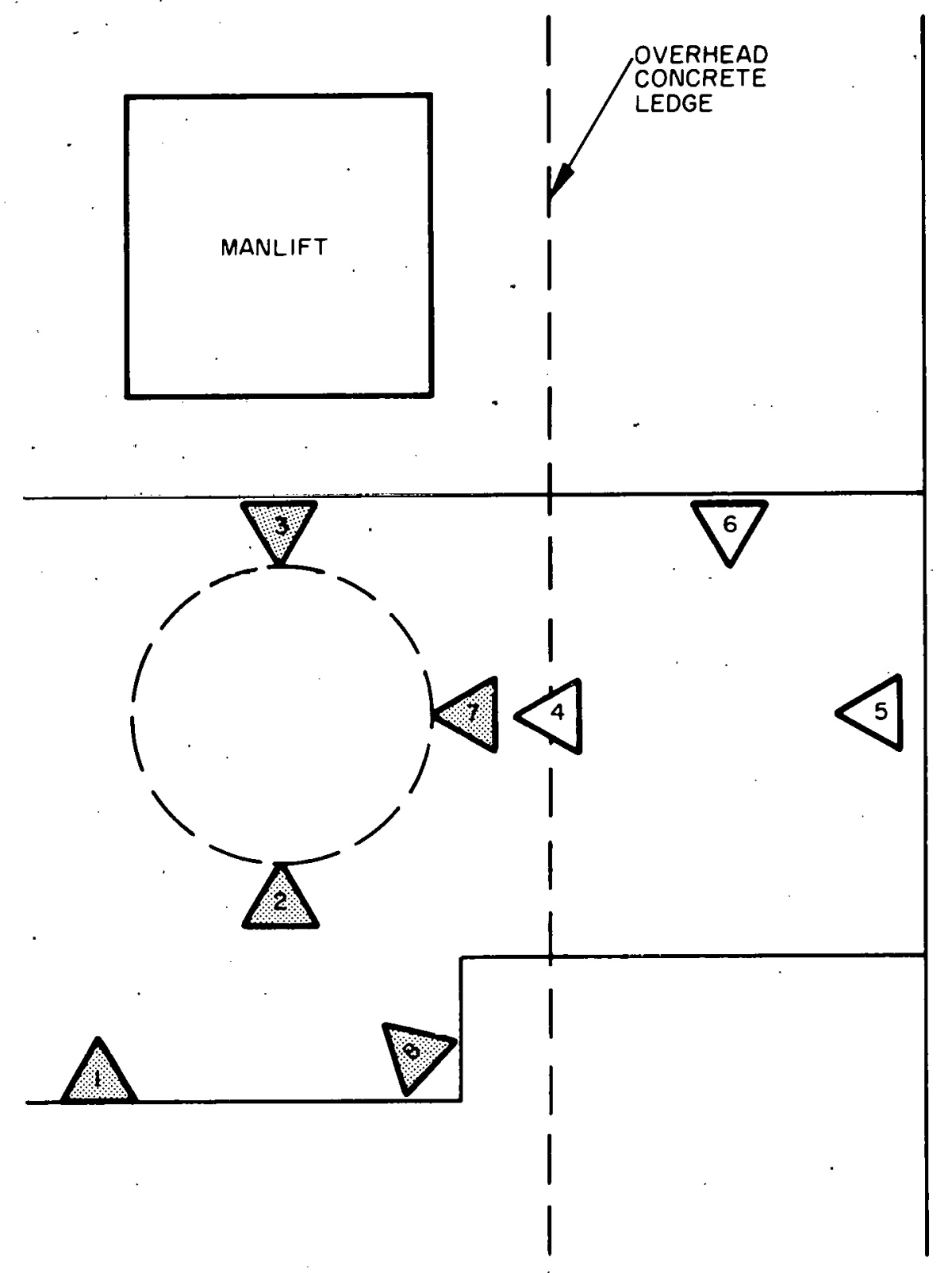

BI STAND FIRST LEVEL PLATFORM
1. $W \mathbb{B} \mathbf{B}$
$\mathrm{H} 6 \mathrm{O}$
F 2.2
3. $\begin{array}{ll}W & 2.1 \\ H & \frac{\mathrm{B}}{4} \\ \text { F } & 0.7\end{array}$
5. \begin{tabular}{ll}
$W$ & 0.5 \\
F & 0.6 \\
\hline & 0.5
\end{tabular}
7. $\begin{aligned} & W \\ & H \\ & F \quad 0.5\end{aligned}$
$W=$ MR/HR AT WAIST
2. $W 3.4$
$\mathrm{H}$.
4. $W$ 1.6
H 1.8
6. W $\frac{0.6}{0.5}$
F 1.0
H. $\frac{0.5}{0.6}$
$\begin{array}{ll}8 & W 0 \\ H & \\ \text { F } & 2.0\end{array}$
$H=M R / H R$ AT HEAD
$F=M R / H R$ AT FEET

Figure 20. Sample Area Radiation Survey Map (CMAA) 
wear around the gloveport occurred and stretching of the glove was required during manufacturing operations. Their use reduced glove failures in these gloveboxes by about 25 percent.

Radiological work practices were improved through periodic training sessions and all shift surveillance operations. Procedures were prepared or revised promptly to correct deficiencies. Equipment and tools were redesigned if found to be inadequate, and malfunctioning frisking equipment was upgraded.

The need for total containment for repair operations on equipment exposed to the fuel resulted in the development of tent and PVC plastic bag enclosures and improvements in clothing requirements, breathing air requirements, and procedures for removal of contaminated clothing from personnel exiting from tents.

\section{B. Radiation Exposure Control}

The LWBR core is a developmental core and, as such, a total of about 1500 rem whole-body exposure was recorded during the manufacture of this core.

LWBR core manufacturing personnel radiation exposures were controlled at levels well below the 5 rem yearly limit of References 1 and 2 for wholebody and critical organ exposure to penetrating radiation. The highest yearly exposure recorded for an individual was 2.93 rem with an average annual exposure for the manufacturing personnel of about 1 rem. The yearly average exposure experienced by personnel in the binary powder and pellet manufacturing areas was about $1.1 \mathrm{rem} / \mathrm{yr}$. This compares with a projected exposure of $1.5 \mathrm{rem} / \mathrm{yr}$ based upon the shield design and manufacturing operation evaluations (Appendix B). The yearly average exposure experienced by fuel rod processing personnel was about $0.6 \mathrm{rem} / \mathrm{yr}$ compared with a projected exposure of $0.75 \mathrm{rem} / \mathrm{yr}$ (Âppendix B). For core assembly personnel, the yearly average whole body exposure was about $1.1 \mathrm{rem} / \mathrm{yr}$ compared with a projected exposure of $1.2 \mathrm{rem} / \mathrm{yr}$ (Appendix B). An average annual exposure to the hands was approximately $3.2 \mathrm{rem} / \mathrm{yr}$ as compared with a projected exposure of $11.8 \mathrm{rem} / \mathrm{yr}$. This was accomplished through Bettis Laboratory management's commitment to maintain radiation exposures as low as was reasonably achievable. T'he Rem Reduction Program was coordinated and developed with Radiological Control and LWBR core management by the special LWBR core group established specifically to reduce radiation exposures and improve contamination control.

\section{Lessons Learned}

To improve radioactive contamination and radiation exposure control in similar manufacturing operations, the following items should be considered.

\section{Contamination Containment Criteria}

a. Provide total containment for the handling and processing of all unclad fuel materials, including $\mathrm{ThO}_{2}$.

b. Design all manufacturing facilities such that the flow of fuel material through the facility minimizes both handling requirements and the removal from total containment, where used.

c. Design gloveboxes, equipment, and tunnels such that they will:

1) Eliminate glovebox glove teariny and cutting hazards

2) Provide easy access to equipment and tools in the boxes to reduce glovebox glove stretching

3) Reduce crowding and increase visibility inside gloveboxes to reduce bumping and snagging of gloves.

4) Eliminate any crevices or inaccessible areas where contamination can collect, including providing accessibility for cleaning using glovebox gloves.

d. Obtain improved glovebox gloves to reduce the number of glove failures.

e. Design and locate HEPA filters lor easiet replacement. (HEPA filters were installed above gloveboxes and many were accessible only through the use of ladders.)

t. Design gloveboxes to contain only that portion of equipment, such as presses and grinders, that must contact fuel rather than totally enclosing the equipment in the glovebox; this would substantially reduce the amount of maintenance and repair required on contaminated equipment.

g. Pruvide alpha friskers for frisking upper arm and upper budy dreas as well as hands when coming out of glovebox gloves. (Alpha hand friskers were useful only as hand and lower arm friskers.)

h. Provide improved decóntamination facilities. (Because no glovebox or contained decontamination facilities were provided, any tool or equipment decontamination had to be carried out in temporary containments.) 
i. Improve communications in tent containments for repair operations. (With forced air breathing apparatus required, the resulting noise level made communications very difficult.)

j. Design facility exhaust systems so that Oxylene (an azeotropic mixture of approximately 80-percent Freon-113 (trichlorotrifluoroethane) and 20-percent methylene chloride vapors) are not passed through charcoal filters used for minimizing the release of ${ }^{220} \mathrm{Rn}$ to the atmosphere. (Testing showed that Oxylene is absorbed on the charcoal filters, reducing their intended effectiveness for retention of ${ }^{220} \mathrm{Rn}$.) Consideration should be given to condensing the oxylene from the exhaust air at the gloveboxes in which it is used and volatilized, or providing a separate exhaust system for operations involving the use of Oxylene.

\section{Radiation Exposure Reduction}

a. Reduce direct handling of fuel and fuel components.

b. Provide adequate radiation shielding on all fuel processing, inspection; and rod assembly equipment. c. Design gloveboxes and connecting tunnels so that there are no places to trap fuel powder or pellets, and so that the boxes can be readily inspected and cleaned. This would reduce the buildup of radiation levels, including hot spots, in the boxes and tunnels and would permit easy inspection for loose pellets.

d. Install gloveboxes and other equipment with sufficient space separations to reduce the buildup of radiation fields due to interaction of radiation fields from the equipment.

e. Provide sufficient shielded storage space for fuel pellets, rods, and scrap.

\section{ACKNOWLEDGEMENTS}

Contributions to this report were provided by N. E. Gordon, D. L. Harrison, R. A. Knopf, P. A. Ombrellaro, S. P. Stern, T. W. Thompson, F. A. Turski, and B. L. Twitty of the Bettis Laboratory Radiation and Safety Activity.

\section{REFERENCES}

1. Department of Energy (DOE) Manual Chapter 0524.

2. Title 10, Code of Federal Regulations, Part 20 (10CFR20). 
APPENDIX A

RADIOLOGICAL SURVEILLANCE PLANLWBR CORE MANUFACTURING PROGRAM 


\section{APPENDIX A}

\section{RADIOLOGICAL SURVEILLANCE PLAN- LWBR CORE MANUFACTURING PROGRAM}

\section{INTRODUCTION}

A comprehensive radiological surveillance program was established as an integral part of the LWBR Core Manufacturing Program. The surveillance program included monitoring and surveys as required to confirm compliance with the radiological controls and limits specified in Section III of the report and applicable radiological control documents. The emphasis of the program was to identify potential problems early enough to preclude exceeding the appropriate limits or control guides.

An outline of the surveillance program follows. Throughout the outline the word fuel means materials containing thoria, urania, or any combination of the two.

\section{MONITORING FOR AIRBORNE RADIOACTIVITY}

\section{A. General Air Sampling}

Sampling for airborne radioactivity, both alpha and beta-gamma, was performed in LWBR facilities processing unclad fuel. Constant flow, fixedfilter air samplers were located to provide representative air samples for measurement of any particulate airborne radioactivity in the work area atmospheres. Samplers were operated continuously during fuel processing operations and provided detection of general airborne radioactivity levels at or below $1 / 10$ the applicable Concentration Guide for 8-hour (minimum) sampling periods. Sampler filters were collected every 24 hours under normal operating conditions and were counted for alpha and beta-gamma emissions.

About 90 samplers were located in the Binary Development work areas (see Figure 5 of the report for approximate locations); 30 samplers were located in the W5L N-Building work areas; and 7 samplers were located in the RA Building work areas.

\section{B. Continuous Air Monitors}

The Binary Development fuel process areas were serviced by 13 continuous air monitors. These units were portable and were located to provide prompt detection and representative monitoring of airborne alpha activity. Alpha activity was monitored because, in the event of airborne radioactivity, alpha activity was detectable before betagamma activity because of the radionuclides in- volved in fuel areas. The continuous air monitors utilized solid state electronics to provide energy discrimination to factor out natural airborne activity which fluctuated with weather conditions. The units activated visible and audible alarms when airborne alpha activity in the area exceeded the applicable Concentration Guide for 4 hours. Similarly, the units would alarm after 2 hours at twice the Concentration Guide or after 8 hours at one half the Concentration Guide. The recirculating air from the North, South, and Chemistry areas was monitored by three additional continuous air monitors which initiated alarms on the Central Alarm Panel if limits were exceeded.

\section{Gaseous Effluent (Exhaust) Monitoring}

All exhaust air streams from LWBR facilities or operations involving unclad fuel were continuously sampled for alpha and beta-gamma airborne activity by constant flow, fixed-filter air samplers. Samples detected exhaust radioactivity at or below $1 / 10$ the applicable release limits for 8-hour (minimum) periods. Additionally, the exhaust air from the Binary Development Area was monitored with an air monitor that continuously sampled and analyzed for gross alpha activity in the exhaust stream. The unit activated visible and audible alarms, both locally and at the Central Alarm Panel, if the exhaust activity exceeded the applicable Concentration Guide for 4 hours. Similarly, the units would alarm after 2 hours at twice the Concentration Guide or after 8 hours at one half the Concentration Guide.

The Binary Development Area had a single exhaust stack with a continuous sampler and an air monitor. W5L N-Building had five exhaust stacks with a continuous sampler on each. 'I'he RA Building had two exhaust stacks with a continuous sampler on each.

\section{AREA RADIATION MONITOR- ING}

\section{A. Continuous Area Gamma Moni- tors}

Continuous monitoring of work area radiation levels was provided in the Binary Development and Core Manufacturing Assembly areas. Eight detector units in each area were connected to visible and audible alarms and to chart recorders at the control console in each facility. The area monitors provided information regarding general area 
levels for use in reducing personnel exposures and helped to detect any abnormal changes in exposure rates during supposedly normal operations which could result in added exposure to personnel.

Radiation Control adjusted each individual monitor to a practical alarm setting as exposure rates under normal conditions were established. Radiological Control was notified as each new phase of operations started (and of any significant changes in the measured levels) so that it could evaluate the settinqs.

\section{B. Startup Surveys}

Radiation surveys with portable instruments were conducted by Radiological Control during initial fuel processing at all work stations to verify the integrity and adequacy of shielding and to define work station radiation levels. Such surveys were repeated as required by signiticant changes in operations. The types of surveys conducted in each area were as lullows:

1. Binary Development Area-beta-gamma and neutron surveys

2. Ceramic Processing Facility-beta-gamma surveys

3. Fuel Rod Facility-beta-gamma and neutron surveys.

\section{Routine and Other Special Sur- veys}

Routine radiation surveys were performed at least weekly by Radiological Control in all fuel handling areas. At this time the location of the $0.5 \mathrm{mrem} / \mathrm{hr}$ tape, denoting radiation areas of $0.5 \mathrm{mrem} / \mathrm{hr}$ or less, was verified or changed if required. Additionally, surveys were performed to control personnel radiation exposures prior to and/or during nonroutine operations or abnormal conditions that might be expected to change area radiation levels.

\section{CONTAMINATION MONITOR- ING}

\section{A. Personnel Frisking}

All personnel exiting from unclad fuel handling areas (Binary Development Área and Ceramic Processing Facility) were required to frisk their whole bodies for possible contamination. All such areas were controlled areas and alpha frisking equipment was provided at the area exits. Personnel were trained in the proper technique for frisking. Personnel frisking during shift changes was routinely monitored by Radiological Control and intermittently throughout the work shifts. Frisking practices were also monitored on an intermittent basis by management and special surveillance groups.

Personnel contamination frisking in the LWBR fuel manufacturing areas was accomplished with alpha sensitive probes. These probes were sensi. tive to less than 50 picocuries of alpha activity. Calculations which were confirmed by experimental data indicated the relative yields of alpha and heita artivity from 5 yoar old thorium (the aye at which the alpha-to-beta ratio is lowest) to be 1.87 to 1 . That ratio was further increased in ${ }^{233} \mathrm{UO}_{2}-\mathrm{ThO}_{2}$ blends, i.e., alpha-to-beta ratio of 200 to $\mathrm{l}$ for a $5.8 \mathrm{w} / \mathrm{o}{ }^{233} \mathrm{U}$ blend. The alpha-tobeta ratio combined with detector efficiencies produced an overall detection sensitivity for $\mathrm{ThO}_{2}$ or ${ }^{233} \mathrm{UO}_{2}-\mathrm{ThO}_{2}$ which favored the alpha detector by a factor of almost two. Although self-absorption of the alpha reduced sensitivity of personnel monitors, a comparable nr greater loss of sensitivity of the beta detector due to bela-gamma background was experienced.

\section{B. Laundry Monitoring}

Anticontamination clothing was required for entry in to the controlled surface contamination area. This clothing was laundered by a contractor vendor. Other clothing was supplied for use outside the controlled surface contamination area and was handled separately from anticontamination clothing by another vendor. It was treated as radiologically clean but was surveyed for contamination at a control facility prior to releasing it to the laundry vendor. These controls provided an additional check as to the adequacy of personnel monitoring.

\section{Area Monitoring}

\section{Ceramic Processing Facility}

a. W5L N-Building was operated as a controlled surface contamination area. Routine alpha contamination surveys of surfaces in this area were performed by Radiological Control every other work day. Installed temporary contamination containment devices (tents or PVC plastic bag enclosures) were insperted daily and approved for use.

b. The RA Building was surveyed for alpha contamination every other work day to ensure that the area was maintained as a clean area. 


\section{Binary Development Area}

Routine area alpha contamination surveys were conducted by Radiological Control every other work day and during and/or following special or nonroutine operations or conditions such as process equipment repairs, glove ruptures or replacements, and filter changes. Included in these surveys were spot checks on glovebox gloves and the inspection and approval of all installed temporary contamination containment devices.

The fuel processing areas were controlled areas, but were maintained within clean limits. Unclad fuel was not handled outside gloveboxes or hoods (for thoria) without proper packaging to control radioactivity release. Small alpha detectors for frisking personnel, protective gloves, and lower purtions of work coverall sleeves were located throughout these areas such that one of the friskers was within a few feet of any work station. Operating personnel in the manufacturing areas were required to check their gloved hands for alpha contamination immediately after removing their hands from the glovebox gloves to prevent the spread of contamination in the event of a glovebox glove failure.

Any time contamination was detected outside of gloveboxes or hoods, all work and movement in the localized area was halted. Radiological Control was called in and the area personnel were not released until clean limits were reestablished.

Two Binary Development Areas were operated as locally controlled work zones. These two work zones, in which there was greater potential for releasing fuel from the boxes, included the gloveboxes in which fuel powder was handled and the boxes in which pellet grinding was done. Personnel leaving these work zones were required to frisk their whole bodies. This requirement, combined with the practice of personnel monitoring their protective gloves and sleeves immediately after working in a glovebox, provided early identification of qlove leaks or other breaches in the containment, thus allowing correction before contamination could be spread.

The location of the controlled areas, local work zones, radiation monitoring and frisking equipment, and traffic patterns are shown in Figure 5 of the report. The disposition of the monitoring equipment in those areas supported the above approach to contamination monitoring and control.

\section{Material Surveys}

All equipment and materials removed from gloveboxes, controlled work areas, and controlled surface contamination areas were monitored to provide additional assurance that the items, or outer surfaces of their packaging, met clean limits.

\section{LIQUID WASTE MONITORING}

All process liquids which came in contact with unclad fuel were placed in nuclearly safe containers and assayed for fuel content. They were evaporated and/or solidified, packaged, and shipped to NRC or DOE-approved burial or storage facilities. Liquids which could potentially have been contaminated in excess of applicable release limits were cycled through liquid waste processing systems and analyzed to ensure that the limits of References 1 and 2 were not exceeded. Solutions which were sampled and found to be above release limits were either evaporated and/or solidified or processed through liquid waste processing systems until below the limits.

\section{SOLID WASTE MONITORING}

Wastes generated in controlled access work areas but outside of surface contamination control areas were not considered contaminated. These wastes were monitored and disposed of as nonradioactive waste.

Contaminated wastes, such as gloves, rags, etc., generated in binary fuel processing gloveboxes were placed in nuclearly safe containers and assayed for fissile content. Depending on the value of the assay the containers were either placed in drums for disposal as radioactive waste or were placed in nuclearly safe storage devices. Waste from the chemistry gloveboxes, thoria boxes or hoods, and controlled surface contamination areas were placed in yellow polyethylene bags and placed in drums for disposal as radioactive waste.

Waste drums were surveyed by Radiological Control prior to transfer to indoor storage areas. Waste storage areas were surveyed by Radiological Control as required in Reference 1 for radiation areas. Waste containers and shipments were surveyed prior to shipment off-site to ensure compliance with applicable federal regulations.

\section{PERSONNEL MONITORING}

\section{A. External Exposure Monitoring}

All personnel assigned to work and handle fuel in the LWBR core manufacturing areas were assigned and required to wear dosimetry badges and pocket dosimeters. Additionally, all visitors to such areas were issued and required to wear dosimetry badges while in the areas. Dosimetry badges utilized thermoluminescent dosimeters (TLD) as the exposure detectors. Dosimetry badges were processed on a monthly or quarterly basis depending upon whether more than $100 \mathrm{mrem}$ exposure was expected in a 3 -month 
period. Pocket dosimeters were rezeroed when they read between 100 and $150 \mathrm{mrem}$. (See Section IV.F of the report for details on reporting of dosimetry data and its evaluation.)

\section{B. Internal Exposure Monitoring}

Personnel assigned routine duties in areas handling unclad ${ }^{233} \mathrm{UO}_{2}, \mathrm{ThO}_{2}$, or binary fuel were included in an internal exposure monitoring program. All personnel working with unclad fuel were included in a bioassay program for internal exposure evaluation. All such personnel received a lung count as soon as was practicable to establish their baseline activity levels and upon termination of their assignments. The sensitivity for these measurements was $120 \mathrm{mg}$ or 55 percent of a lung burden for ${ }^{233} \mathrm{U}$ and $7.0 \mathrm{mq}$ or 24.0 percent for thorium.

Additionally, personnel were scheduled for special lung counting and/or urine and fecal analyses if there was any reason to suspect a possible internal exposure as the result of a problem. The sensitivity of urine and fecal analysis was approximately 10 percent of a body burden for ${ }^{233} U$ or thorium.

\section{Extremity Monitoring}

Extremity dosimeters were issued to sel $\cdot$ ed operating personnel whose extremity exposures would be representative of the various operator assignments involving contact handling of fuel materials. Extremity dosimeters normally monitored hand exposures by means of a thermoluminescent dosimeter (TLD) placed in a ring-type holder. Local exposures to other body locations (e.g., arms, feet, etc.) were also measured using TLD's. Extremity dosimeters were read and evaluated at the same time dosimeter badges were read. Corrective actions were taken as indicated by the data. 


\section{APPENDIX B}

\section{SHIELD DESIGN BASIS AND PERSONNEL EXPOSURE ESTIMATES}

\section{INTRODUCTION}

The shielding requirements for the LWBR core facilities and equipment were established by making personnel radiation exposure estimates using the estimated fuel radiation levels and the estimated personnel stay-times at each work station for each of the major manufacturing processes: (1) powder and pellet production, (2) fuel rod manufacture, and ( 3 ) core assembly operations. The exposure estimates for each of these categories are summarized below.

The shield design basis for manufacturing and assembly operations was established on a maximum quarterly exposure limit of $1.25 \mathrm{rem}$. However, because of large variations in the quarterly fuel inventories, the expected annual average radiation exposure that would be received by personnel performing these operations was estimated to be less than $1 / 3$ the 5.0 rem annual limit. This estimate took advantage of known conservatisms in the factors and parameters used in the shield design calculations, average fuel loadings which would most likely be in the line during the manufacturing and assembly operations, and the most likely stay times for personnel. Thus, the shield design basis and the way it was used was consistent with the concept of maintaining personnel exposures at the lowest practicable levels.

\section{POWDER AND PELLET PRO- DUCTION}

The radiation levels associated with the binary fuel used in the shielding calculations were based on a ${ }^{232} \mathrm{U}$ impurity level of $8 \mathrm{ppm}$. The actual impurity level in the fuel averaged $7.5 \mathrm{ppm}$. Because radiation levels are proportional to the ${ }^{233} \mathrm{U}$ concentration levels, some conservatism (approximately 6 percent) resulted from this difference

The largest single factor affecting the design 'versus the actual dose rate was the fuel age. The design fuel age (of ${ }^{23} \mathrm{UO}_{2}$ ) was assumed to be . 120 days to the end of the sintering furnace operation. For finished rods the fuel age was assumed to be 250 days. The gamma source strength from the decay of isotopes in the thoria decay chain was thus that which would exist after 120 and 250 days of isotope formation (see Figure l of the report).

In practice, the fuel was expected to be approximately 40 days old when it arrived at Bettis, and it was expected that fuel pellet manufacture would require 10 days. An additional 20 days was required to finish the pellets and load them into the fuel rods. However, routine problems in manufacturing could cause the fuel age to be greater than 50 and 70 days at the end of these manufacturing steps. A best estimate of fuel age was 60 and 120 days, which lead to a factor of two difference between the source strength that was used as the basis for shielding design and the dose rates actually expected to be encountered. This meant that the measured dose rates at a shield design point would be one half the design value or less based on meeting the projected fuel processing dates. The net result of all factors considered was that the projected best estimate yearly exposure to personnel in the powder and peller manufacturing areas would be about 30 percent of the annual expccure limit or $1.5 \mathrm{rem} /$ year.

\section{FUEL ROD PROCESSING}

The projected radiation exposures from processing LWBR core fuel was based on information gained from personnel monitoring procedures implemented during early binary rod preproduction operations. Each fuel rod processor wore nine supplementary thermoluminescent dosimetry devices (TLD's) located on his hands, torso, arms, waist, knee, and forehead. Radiation level measurements were performed with TLD's located around a single fuel rod and a box of fuel rods located in an open storage cask to represent the fuel processor's radiation exposure at various work stations. Time and motion studies were performed to determine the time processors would spend in the various operational radiation fields. In making the exposure projections it was assumed that the average binary fuel ages in the Binary Development Area and the $\mathrm{BC}$ Aisle were 170 and 205 days, respectively. On the basis of this fuel age assumption, the addition of some shielding, and experience with early binary rod operations, an average radiation exposure to a fuel rod processor was projected to be $0.75 \mathrm{rem} / \mathrm{yr}$

\section{CORE ASSEMBLY OPER- ATIONS}

In estimating exposures resulting from the core assembly operations, an average fuel age of 600 days was used. For those operations involving single rods, the dose rates used were those resulting from the highest loaded rod of each type (seed or blanket). For operations involving a fuel assembly, the dose rate estimate considered the averaged fuel loading for all rods, however the completed assembly was assumed to be present 
throughout the entire operation. In reality, the assembly resulted by bringing it together rod by rod. The number of inspections to be performed, the distances separating an operator from the fuel, and the time required for performing the operation were the best values available from inspection requirements identified for early operations and from prototypical assembly operations performed with rods which did not contain fuel. The dose estimates projected for the core assembly personnel were an average annual exposure of $11.8 \mathrm{rem} / \mathrm{yr}$ to the hands and an annual average whole-body exposure of $1.2 \mathrm{rem} / \mathrm{yr}$. 
APPENDIX C

TYPICAL AVERAGE MONTHLY PERSONNEL RADIATION EXPOSURES 


\section{APPENDIX C \\ TYPICAL AVERAGE MONTHLY \\ PERSONNEL RADIATION EXPOSURES}

Area

Typical Average Monthl Exposure per Man, mrer.

Ceramic Processing Facility

Thoria processing

Powder preparation

80

Compacting

55

Preheat and sinter furnaces

Grinding

Vault custodian

Inspection

\section{Binary Development Area}

Powder Preparation

Weighing and blending

Micronizing

Agglomerating

Pellet Compaction

Compacting

Scrap packaging

Furnaces

Pretreat and sinter furnaces

Pellet Grinding

Sludge furnaces

Pellet grinding

Quality control dimension and transfer

Fuel Rod Loading

Degas furnaces

Pellet quality control inspection

Fuel rod loading

Welding and rod transfer

Machining end cap and acid cleaning

Ultrasonic weld inspection

Metallographic and quality control lab 30

Vault custodians

Fuel Rod Facility

BC Aisle (Fuel rod operations)

Bow straiqhtness

Weld bead, concentricity, and perpendicularity

Ultrasonic wall thickness

Helium leak testing

Picker X-ray

In-motion X-ray

Vapor blasting 
Fuel Rod Facility (Cont)

Repair, perpendicularity, and concentricity 50

$\begin{array}{ll}\text { Vault custodians } & 60\end{array}$

Pickling $\quad 30$

Corrosion $\quad 20$

Visual corrosion $\quad 40$

Final dimension $\quad 35$

Final clean and neolube $\quad 60$

\section{CMÃA}

Core assembly manufacturing

100

Core assembly inspection

110 